\title{
Invited review: Animal-based indicators for on-farm welfare assessment for dairy goats
}

\author{
M. Battini, ${ }^{*}$ A. Vieira, $\uparrow$ S. Barbieri, ${ }^{*}$ I. Ajuda, $†$ G. Stilwell, $†$ and S. Mattiello*1 \\ *Università degli Studi di Milano, Dipartimento di Scienze Veterinarie e Sanità Pubblica, 20133 Milano, Italy \\ †Faculdade de Medicina Veterinária, Universidade de Lisboa, 1300-477 Lisboa, Portugal
}

\begin{abstract}
This paper reviews animal-based welfare indicators to develop a valid, reliable, and feasible on-farm welfare assessment protocol for dairy goats. The indicators were considered in the light of the 4 accepted principles (good feeding, good housing, good health, appropriate behavior) subdivided into 12 criteria developed by the European Welfare Quality program. We will only examine the practical indicators to be used on-farm, excluding those requiring the use of specific instruments or laboratory analysis and those that are recorded at the slaughterhouse. Body condition score, hair coat condition, and queuing at the feed barrier or at the drinker seem the most promising indicators for the assessment of the "good feeding" principle. As to "good housing," some indicators were considered promising for assessing "comfort around resting" (e.g., resting in contact with a wall) or "thermal comfort" (e.g., panting score for the detection of heat stress and shivering score for the detection of cold stress). Several indicators related to "good health," such as lameness, claw overgrowth, presence of external abscesses, and hair coat condition, were identified. As to the "appropriate behavior" principle, different criteria have been identified: agonistic behavior is largely used as the "expression of social behavior" criterion, but it is often not feasible for on-farm assessment. Latency to first contact and the avoidance distance test can be used as criteria for assessing the quality of the human-animal relationship. Qualitative behavior assessment seems to be a promising indicator for addressing the "positive emotional state" criterion. Promising indicators were identified for most of the considered criteria; however, no valid indicator has been identified for "expression of other behaviors." Interobserver reliability has rarely been assessed and warrants further attention; in contrast, short-term intraobserver reliability is frequently assessed and some studies consider mid- and long-term
\end{abstract}

Received September 17, 2013.

Accepted July 5, 2014

${ }^{1}$ Corresponding author: silvana.mattiello@unimi.it reliability. The feasibility of most of the reviewed indicators in commercial farms still needs to be carefully evaluated, as several studies were performed under experimental conditions. Our review highlights some aspects of goat welfare that have been widely studied, but some indicators need to be investigated further and drafted before being included in a valid, reliable, and feasible welfare assessment protocol. The indicators selected and examined may be an invaluable starting point for the development of an on-farm welfare assessment protocol for dairy goats.

Key words: animal-based indicator, welfare assessment, dairy goat, on-farm protocol

\section{INTRODUCTION}

Consumer demand for assurance schemes of highquality animal products, in terms of health, safety, and respect of animal welfare, has been increasing over the last few decades. In response to this demand, the assessment of animal welfare at the farm level has become one of the most debated issues in the field of animal husbandry. This topic has been widely discussed at the international level, and species-specific protocols for onfarm welfare assessment are presently a major concern worldwide and for European Union (EU) agricultural policy (Blokhuis et al., 2013).

Welfare assessment requires a multidimensional approach (Mason and Mendl, 1993), corresponding to a multi-criteria evaluation issue, and it should aim to determine the actual welfare of animals, including both their physical and mental state (EFSA, 2012). Different indicators need to be included in efficient welfare assessment schemes, as all are important and they cannot compensate for each other (Blokhuis et al., 2010).

In 2008, the EU Welfare Quality project re-elaborated the concept of the "Five Freedoms" of animals (Brambell Committee, 1965) and defined 4 main areas of animal needs ("Welfare Principles"), which were then split into 12 independent criteria (Blokhuis et al., 2010; Rushen et al., 2011), each of which corresponded to a key welfare question. Welfare principles and criteria are as follows: 
1. Good feeding: absence of prolonged hunger, absence of prolonged thirst;

2. Good housing: comfort around resting, thermal comfort, ease of movement;

3. Good health: absence of injuries, absence of disease, absence of pain induced by management procedures;

4. Appropriate behavior: expression of social behaviors, expression of other behaviors, good human-animal relationship, positive emotional state.

Each criterion includes specific indicators that may be used to assess each component of welfare (Rushen et al., 2011). Although the same indicator may provide information related to different welfare concerns, criteria are independent of each other and form a basic but complete list (Blokhuis et al., 2010).

Two broad categories of indicators can be used to assess animal welfare at the farm level: animal-based and resource-based indicators (Main et al., 2003). The need to focus on animal-based indicators emerged clearly from the EU Welfare Quality project (Blokhuis et al., 2010); however, few available indicators are centered directly on the animals (Johnsen et al., 2001) and they rarely target small ruminants. A recent review on the monitoring of on-farm welfare in small ruminants points out only a few animal-based candidate indicators and most deal with sheep (Caroprese et al., 2009). Resource-based indicators have been more frequently adopted in welfare assessment protocols, because measurements taken are usually quick and easy [e.g., the Animal Needs Index TGI 35L developed by Bartussek (1999) for several species]. Nevertheless, good management and environmental resources do not necessarily result in a high standard of welfare (Winckler, 2006). An animal-based approach seems more appropriate for measuring the actual welfare state of the animals. This represents a considerable change in perspective, a shift from a scheme that mainly measured environmental aspects (which may show high variation from country to country due to different housing and management conditions) toward one that measures the way in which the animal itself responds to such an environment (EFSA, 2012). Furthermore, individuals with different genetic backgrounds (e.g., different breeds) may, in fact, respond differently to the same environment. Although specific examples for goats are not currently available, this has been observed in other ruminant species. For example, in dairy cattle, Mattiello et al. (2011) pointed out that individuals with different genetic backgrounds showed different levels of welfare under similar environmental conditions. This supports the decision to focus mainly on animal-based indicators rather than exclusively on resource-based ones.

The aim of this paper was to review promising animal-based indicators that could be used to set up a valid, reliable, feasible, and practical on-farm welfare assessment protocol for dairy goats, centered on the evaluation of lactating animals.

\section{METHODOLOGY}

This review is part of the Animal Welfare Indicators (AWIN) integrated 7FP project, funded by the European Commission, which is aimed at developing practical on-farm welfare assessment protocols for several species, including goats. Studies carried out for pinpointing animal-based indicators to be included in the protocols are still underway.

A review of the scientific literature to date was the starting point for identifying promising indicators. Databases (Web of Science, CAB Abstracts, PubMed, and Scopus) were searched for English language studies addressing animal-based goat welfare indicators as of (and including) 1990. Key words such as "welfare," "measure," "indicator," "assessment," "disease," "pain," "human-animal relationship," "body condition," and "lameness" were used as major descriptors combined with "goat" or "small ruminant." Most of the reviewed literature dealt with dairy goats; however, although lactating dairy goats are our main target, papers considering other productive categories (e.g., kids, dry goats) and goats farmed for different purposes, or even other species, were taken into account whenever they provided evidence to support the use of indicators that could be included in a nonfarm welfare assessment protocol for lactating dairy goats.

In this review, we refer specifically to the most widespread management system for dairy goats in Europe and North America, which consists of intensive housing systems where goats are kept indoors with occasional access to pasture on some farms. In these systems, dairy goats are usually housed on straw litter, receive a TMR or forage (mainly hay) and concentrate feed once or twice per day, and are milked twice a day in a milking parlor. Kids are usually separated from their mothers early after birth.

We excluded indicators that focus exclusively on resources and management, as well as animal-based indicators that require further laboratory analysis (e.g., metabolic profiling), may be time consuming (e.g., observations performed by video-recording), or may require the use of specific instruments (e.g., stethoscope, thermometer, heart rate monitor, or automatic devices to record behavior; Desnoyers et al., 2009; Mononen et 
al., 2012). We also excluded indicators that could only be recorded at the slaughterhouse.

In addition, we did not include routinely collected herd data, such as milk production and composition or fertility indexes, although we acknowledge their potential importance in assessing animal welfare. These data are often already available in national databases, especially for dairy cows. Their potential value in estimating animal welfare is recognized, even if only as a prescreening tool. In real terms, in dairy cows, such data would seem to indicate a high prevalence of herds with apparent welfare problems, which is not always the case and needs to be confirmed by on-farm assessment (de Vries et al., 2014).

All selected published indicators were classified according to the 4 principles and 12 criteria of Welfare Quality assessment protocols (Welfare Quality, 2009a,b). Some indicators (e.g., BCS and hair coat condition) seemed promising for providing information on more than one criterion. In those cases, validity is discussed in relation to each pertinent criterion.

Promising indicators are summarized in tables, including information on animal category, housing, sample size, validity, reliability, and on-farm feasibility. The latter 3 attributes (see definitions in Table 1) for each potential indicator were previously discussed and agreed upon by a group of experts on goat welfare during a meeting of the AWIN project, held in Milan (Italy) in November 2011.

As AWIN's aim is to have a high level of acceptability from stakeholders in the development of protocols, stakeholder opinion was also taken into account in the drafting of promising indicators. Opinions were collected in different ways: a link to an online survey (translated into 5 languages) was available for $15 \mathrm{mo}$ on the AWIN project website and other institutional sites (e.g., Food and Agriculture Organization of the United Nations); 2 stakeholder meetings were organized (one in Italy and one in Portugal) and attendees were asked to complete a questionnaire. Thirty-eight individuals from different European and non-European countries (e.g., Italy, Spain, Portugal, United Kingdom, United States, Brazil, Mexico, and Australia) answered our online survey, whereas 21 out of 40 people surveyed in Italy, and 11 out of 21 people surveyed in Portugal responded to the questionnaire during the stakeholder meetings. Both the online survey and questionnaire involved veterinarians, farmers, technicians, and advisors. The results of these interviews are reported in the text, when appropriate.

Only the most promising animal-based indicators (in terms of validity, reliability, and feasibility) will be explained and discussed further.

\section{GOOD FEEDING PRINCIPLE}

The good feeding principle considers criteria related to the absence of prolonged hunger and of prolonged thirst by ready access to an adequate diet and fresh water so as to maintain full health and vigor. All the indicators for such these criteria are presented in Table 2 .

\section{Absence of Prolonged Hunger}

Changes in the nutritional status of the animals have a substantial effect on the animal's health and welfare and hence on production. Body condition score is a method for subjective assessment of the nutritional status of farm animals based on the estimation of their body fat. It is considered a valid welfare indicator in many species: cattle (Winckler et al., 2003; Welfare Quality, 2009a,b), buffalo (Winckler et al., 2003; de Rosa et al., 2009), sheep (Russel et al., 1969; Phythian et al., 2011), and goats (Santucci et al., 1991; McGregor and Butler, 2008; Anzuino et al., 2010). Its concurrent validity has been confirmed by Russel et al. (1969) and Santucci et al. (1991), who found that BCS is a good predictor of fat deposits and is highly correlated with carcass fat content. Santucci et al. (1991) also found a significant correlation between body fat content assessed by BCS and fertility, with goats in lower levels of BCS having delays in conception. McGregor and Butler (2008) observed a correlation between BCS and mortality, finding that in cold weather conditions, mortality increased rapidly when the BCS of goats was $<2.0$ (5-point scale). A wide range of BCS systems have been developed and used for research purposes and practical monitoring on commercial farms. The main distinctions among systems are whether they are merely visual or require palpation (or both), and whether the animal is assessed as a whole or separate scores are given for different anatomical regions, which are then summarized or adjusted to give a whole-animal score (as reviewed by Leach et al., 2009a). The assessment of all the reviewed welfare indicators always requires specific training; however, BCS assessment in goats is particularly challenging without specific training and previous experience, because these animals generally have important visceral and internal fat deposits rather than subcutaneous fat (McGregor and Butler, 2008). McGregor and Butler (2008) applied a BCS based on 5-point scale (from 1 to 5 ) identical to that described by Jefferies (1961) for sheep, whereas Santucci et al. (1991) proposed a 6-point scale (from 0 to 5). However, the purpose of including BCS in on-farm welfare assessment schemes is to identify animals that are either too thin or too fat; hence, the scoring system does not need 
BATTINI ET AL.

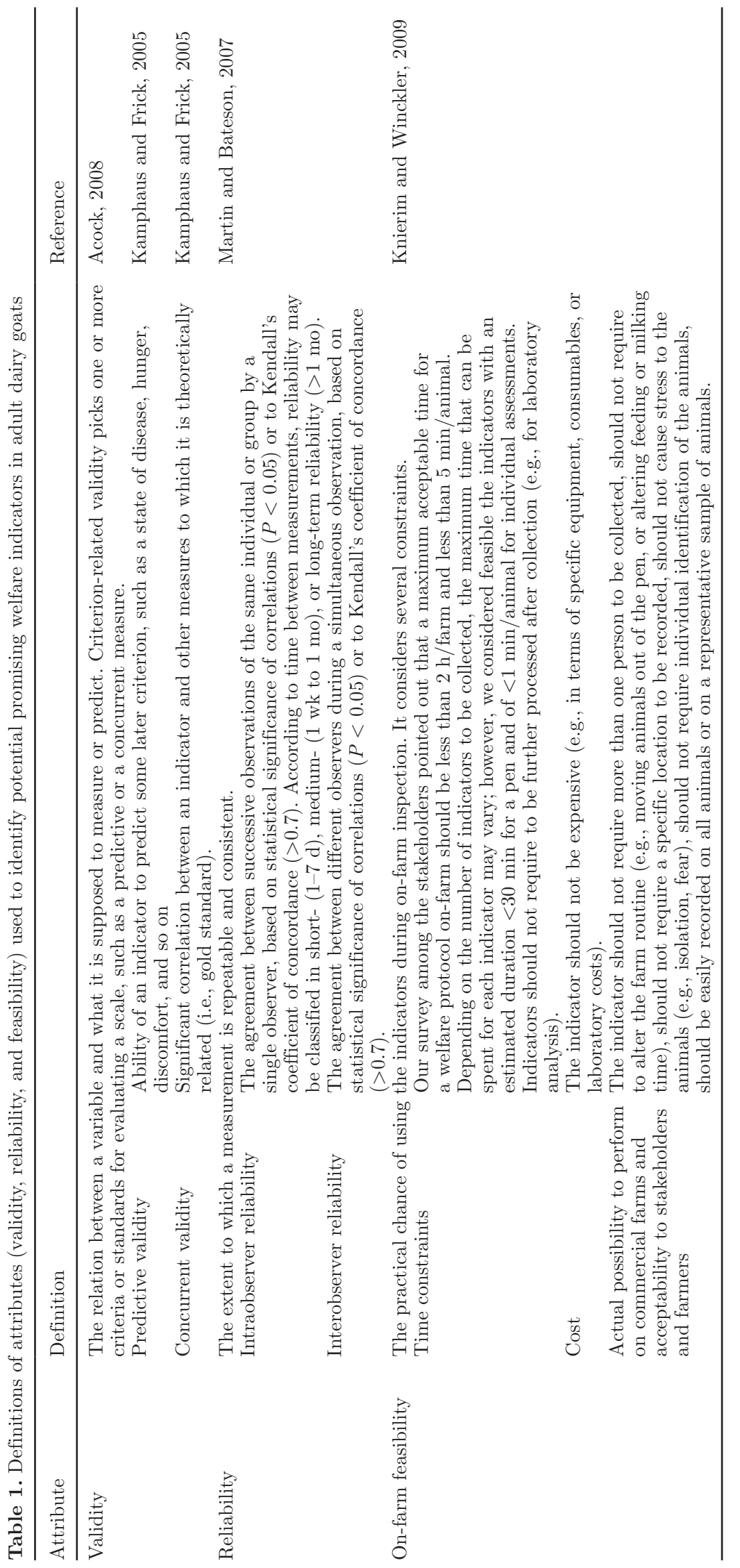




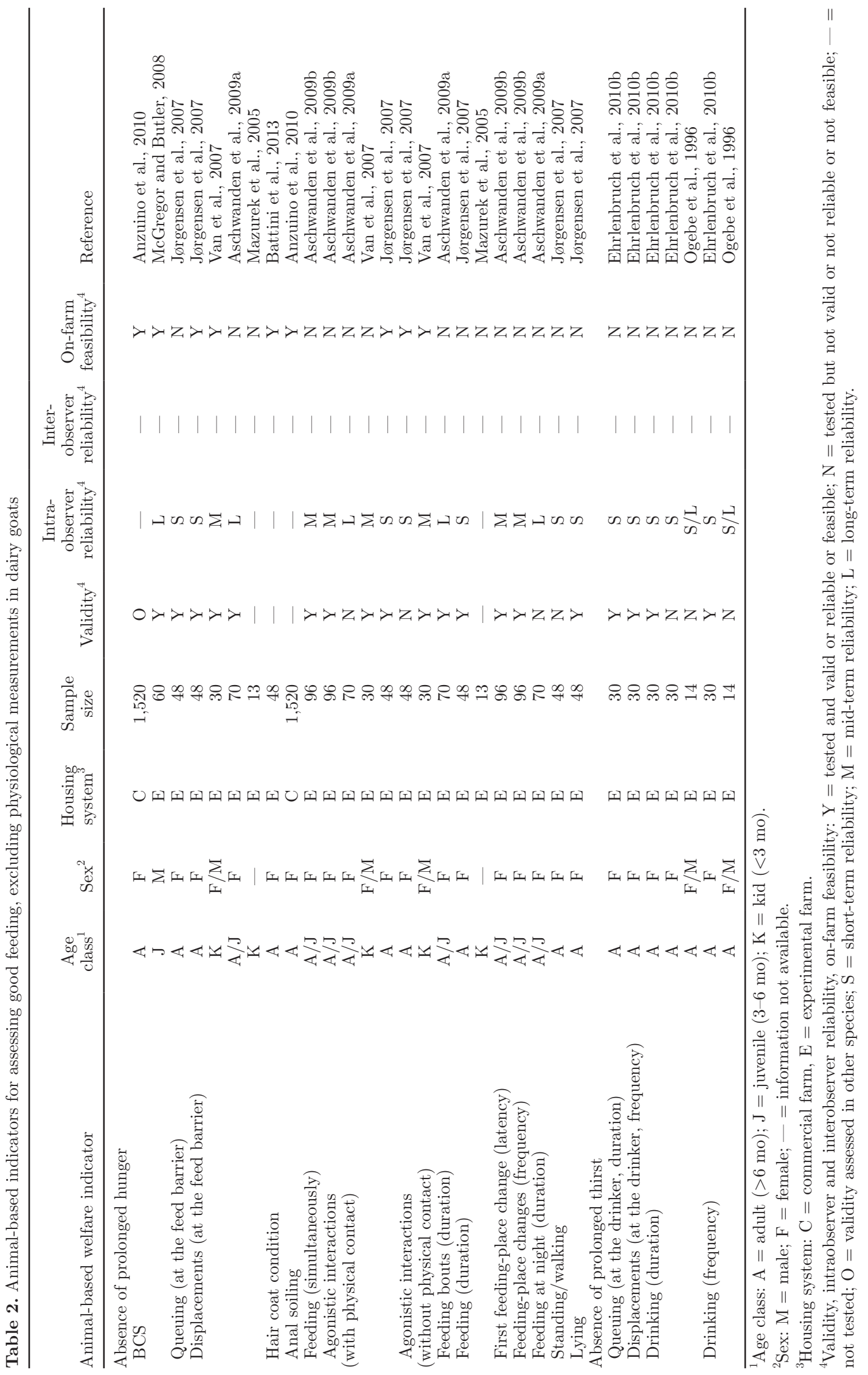


to be extremely detailed. For example, in the welfare protocols for cattle set up by Welfare Quality (2009a), only 3 BCS levels were adopted. This reasoning was followed by Anzuino et al. (2010), who also divided goats into obviously thin and obviously fat animals, differentiating animals by visual appraisal; however, we have no evidence of the validity of this simplified approach. Until now, BCS on goats has been assessed only by palpation, because this seems the most reliable method. However, this procedure requires goats to be individually restrained for palpation, and this is not always feasible in a short time span, especially on large farms. The development of a reliable visual method to highlight animals in extreme nutritional conditions (i.e., too thin or too fat) from outside the pen would be useful to reduce the time required, thus increasing feasibility.

Behavior and social interaction during feeding time can be good indicators to evaluate the absence of prolonged hunger. When given the opportunity (e.g., ad libitum feed distribution), goats may eat up to 7 to 10 h/d (Ferreira et al., 2013): they generally feed during 2 long periods ( $4 \mathrm{~h}$ each; early and late in the daytime), with several small meals in between. On intensive dairy farms, goats usually receive restricted feed twice a day (Görgülü et al., 2008). This management procedure may alter nutritional condition (e.g., reduction in feed intake; Görgülü et al., 2008) and behavioral patterns (e.g., coping strategy; Jørgensen et al., 2007; Görgülü et al., 2008). Feed can be a limited resource because the amount of feed is restricted, or because the feed type and composition are not appropriate (e.g., the roughage:concentrate ratio is too low, therefore feed is consumed very quickly and competition is increased), or because feeding space is not accessible for all individuals in the group at the same time (Jørgensen et al., 2007; Görgülü et al., 2008). In a competitive environment, such as on intensive or semi-intensive dairy farms, these problems can be partly overcome by adopting a coping strategy that consists of consuming the feed at different times of the day to optimize access to the feed trough (Shinde et al., 2004; Jørgensen et al., 2007). However, under these competitive circumstances, low-ranking goats may have access to lower quality feed and may experience a negative emotional state similar to the frustration caused by the time spent queuing at the feed trough. Carbonaro et al. (1992) have documented frustration related to food thwarting in dairy goats, confirming that frustration may elicit physiological alterations (e.g., an increase of norepinephrine) and behavioral reactions (e.g., pawing, head movements, rearing).

Queuing animals at the feeding rack may be a promising indicator, as this behavior is exacerbated by increasing the number of goats per feeding place (Jørgensen et al., 2007), thus confirming its predictive validity. However, the use of 24 -h video-recording adopted by Jørgensen et al. (2007) is not feasible for an on-farm welfare evaluation protocol; hence, different observation strategies need to be explored (e.g., direct data collection per segment/pen in a predetermined timeframe, as already adopted in a dairy cow protocol; Laister et al., 2009). Although goats usually prefer to adopt the queuing strategy to cope with reduced access to feed, displacements also proved to be a valid indicator in assessing absence of prolonged hunger in both adult female goats (Jørgensen et al., 2007; Aschwanden et al., 2009a) and kids (Van et al., 2007), as well as in other species, such as pigs and cattle (Nielsen et al., 1995; Olofsson, 1999). The number of displacements may increase not only in response to a competitive environment (Jørgensen et al., 2007; Van et al., 2007; Aschwanden et al., 2009a), but also in response to feed composition and hence feed preferences (e.g., hay vs. silage, Jørgensen et al., 2007; jackfruit vs. concentrate; Van et al., 2007).

Some researchers suggest that hair coat condition can be used as a first warning of a goat's nutritional status and health (Veit et al., 1993; Smith and Sherman, 2009; Sarkar et al., 2010; Lengarite et al., 2012); this concept is widely accepted by farmers and technicians. Recent research seems to confirm that this indicator can be valid and practical for on-farm welfare assessment, as goats with rough or scurfy hair can be easily identified and present a very low BCS (Battini et al., 2013).

Anal soiling is another interesting indicator of good feeding, as it reflects problems with nutrition and digestion (Grove-White, 2004); namely, ruminal acidosis (Braun et al., 1992). The validity of this indicator has never been assessed in goats, but it is accepted and used in cattle (Leach et al., 2009b). It is considered a feasible indicator for goats (Anzuino et al., 2010); however, it is difficult to assess it in the pen and might be best recorded in the milking parlor.

Jørgensen et al. (2007) considered the video-recorded 24-h time budget of general activity behaviors - feeding, walking, standing, and lying - in relation to hunger (Table 2). Their results confirm the validity of feeding time (that significantly decreased when the number of goats per feeding place increased) but not of the other behaviors considered. Furthermore, a prolonged observation time is required to obtain a reliable figure of the time budget (Martin and Bateson, 2007), which reduces its on-farm feasibility.

Feed intake (difference between weight of daily offered feed and weight of residues) is another valid indicator of the absence of prolonged hunger, as it can be reduced by insufficient space availability (Jørgensen 
et al., 2007). However, this indicator is not measured directly on the animals, is time consuming (in terms of time required to weigh the residual roughage), and therefore is not feasible for our purposes.

\section{Absence of Prolonged Thirst}

Available literature sources give scarce indication as to animal-based indicators for evaluating the absence of prolonged thirst. Ready access to fresh water is important to maintain full health and vigor; welfare can be compromised if animals cannot drink whenever they feel the need to, either because fresh water is not available or because of competition with other goats. Continuous and prolonged lack of access to fresh water may eventually lead to chronic dehydration, especially during hot periods (Ogebe et al., 1996; Darcan et al., 2007).

As mentioned before, although goats may adopt coping strategies in competitive environments (e.g., intensive farms; Jørgensen et al., 2007; Ehrlenbruch et al., 2010b), which may lead to change in social behaviors, they mainly prefer drinking around feeding time (Rossi and Scharrer, 1992). This behavior is generally socially facilitated (Forkman, 1996) and quite synchronized (Rook and Penning, 1991). Reduced possibility of simultaneous drinking can lead to decreased drinking time and hence lower water intake (Ogebe et al., 1996; Van et al., 2007). Queuing animals and displacements at the drinkers may be used to detect animals suffering from thirst. During a 2-h video-recording, Ehrlenbruch et al. (2010b) found increased agonistic behavior and queuing when the ratio of nipples to goats was less than $1: 15$, a situation that may occasionally occur on commercial farms. As already stated, the use of cameras is not feasible for practical on-farm use, because it requires additional time to analyze the recorded information; therefore, other more feasible observation strategies should be identified to collect data regarding these indicators. A possible suggestion may be to concentrate direct observations on queuing animals and displacements at the drinkers within a short time after feeding (Rossi and Scharrer, 1992), making use of suitable observation strategies that need to be specifically validated for this aim.

Other indicators used in previous studies to detect water deficiencies (e.g., respiratory rate, rectal temperature, body mass, daily outputs of urine and feces, hematocrit values and plasma volume; Rahardja et al., 2011; Al-Ramamneh et al., 2012) are not feasible for onfarm welfare evaluation, because they require further laboratory analysis or the use of specific instruments. However, they can be useful for validating other, more feasible, indicators.

\section{GOOD HOUSING PRINCIPLE}

This principle involves criteria related to farm structures and housing conditions. All the reviewed indicators for these welfare criteria are presented in Table 3.

\section{Comfort Around Resting}

As defined in Welfare Quality (2009a), "animals should have comfort when they are resting." When goats have the possibility to choose, they prefer to rest against a wall rather than in the middle of the pen (Andersen and Bøe, 2007; Ehrlenbruch et al., 2010a), as already observed in other farm animals and summarized by Ehrlenbruch et al. (2010a) (cattle: Stricklin et al., 1979; sheep: Marsden and Wood-Gush, 1986; Færevik et al., 2005; Bøe et al., 2006; fowl: Cornetto and Estevez, 2001). This may be due to increased comfort or to an antipredator strategy, suggesting that the animals may feel safer close to a wall than in an open area. If space allowance is reduced, goats are forced to choose different areas, including those without walls, in which to lie down. Resting in contact with the wall showed a predictive validity in Andersen and Bøe (2007) and Ehrlenbruch et al. (2010a) in a lying size area ranging from 0.5 to $1.0 \mathrm{~m}^{2}$ /goat, but not in Loretz et al. (2004), where a larger lying area was provided (1.0 to $2.0 \mathrm{~m}^{2}$ / goat). These findings suggest that, below a given individual space availability, goats cannot choose their preferred resting areas. This supports the hypothesis of using this indicator to detect comfort around resting. Feasibility needs to be improved, as data collection in the cited studies was performed through prolonged video recording, resulting in a method that is too time consuming. Direct observation needs to be further studied before being efficiently applied. Moreover, it is crucial to identify the right moment to observe animals. Generally, they tend to have synchronized resting patterns (Rook and Penning, 1991). However, the percentage of observations when all animals rest simultaneously may vary depending on the size of the lying area; for example, Andersen and Bøe (2007) observed that the percentage of observations with all goats lying simultaneously ranged from $8.5 \%$ at $0.75 \mathrm{~m}^{2}$ /goat to $21.1 \%$ at $1.00 \mathrm{~m}^{2} /$ goat. This suggests that, when enough space is provided, goats tend to rest simultaneously and therefore the level of synchronization can give reliable information about comfort around resting. However, an observation time of $24 \mathrm{~h}$ at 10-min intervals, as used by Andersen and Bøe (2007), cannot be considered feasible for an on-farm protocol.

Goats dislike wet areas when resting. Cleanliness is already used as a valid welfare indicator in pigs (Hughes, 2001), poultry (Scott et al., 2007), and cattle 


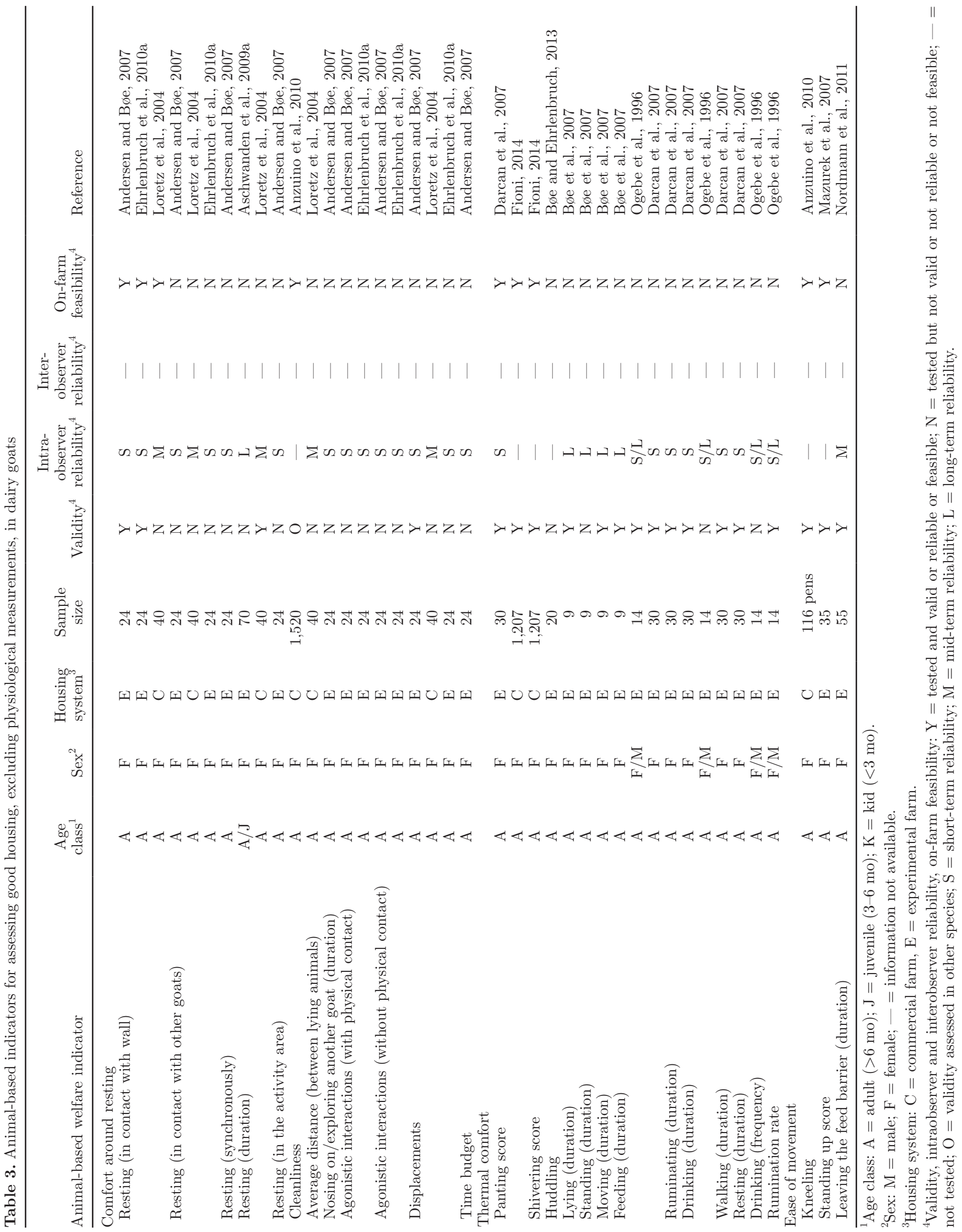


(Andreasen and Forkman, 2012). Dairy goats are much cleaner than dairy cattle, because they generally have drier fecal matter and are usually housed on straw bedding year round. Manure management is much easier in goats than in cattle, but the way in which goats are handled and moved to the milking parlor, as well as the cleanliness and dryness of walkways, may significantly influence the goat's cleanliness. In dairy cattle, the main factors affecting the cleanliness of limbs are the cleaning frequency of barn alleyways, the ease in moving procedures, group density, and the number of times animals are moved (Hughes, 2001; Schreiner and Ruegg, 2003). Anzuino et al. (2010) used cleanliness as a possible welfare indicator; however, the best location to score it has yet to be identified. The milking parlor may be a good location to record cleanliness of the rear body region, but other locations should be identified to gather information about the front body area, such as the sternum region over which goats lie. Observation of cleanliness may be very time consuming in large herds. In these cases, the development of a representative sampling strategy may be required.

Based on previous results by Loretz et al. (2004), Andersen and Bøe (2007) hypothesized that lying time would decrease when space availability was reduced; therefore, they used the 24-h time budget (time spent lying, standing, and moving in the resting area and in the activity area) as an indicator of comfort around resting. However, their results do not support the validity of time budget in relation to comfort around resting. Furthermore, as already mentioned, on-farm feasibility for time budget assessment is low because of the long observation time required (Martin and Bateson, 2007).

\section{Thermal Comfort}

It is known that ruminants have a broad thermal comfort zone and a high degree of thermal tolerance (Sejian and Srivastava, 2010). Scarce information about the limits of thermal comfort, allowing goats to maintain a near-constant body temperature of approximately $39^{\circ} \mathrm{C}$, is available in the literature. Toussaint (1997) suggested that adequate temperatures for goats kept indoors range from $6^{\circ} \mathrm{C}$ to $27^{\circ} \mathrm{C}$ (optimum from $10^{\circ}$ to $18^{\circ} \mathrm{C}$ ), with relative humidity from 60 to $80 \%$. Beyond the limits of thermal comfort, behavioral and physiological changes may occur that reduce or increase the heat loss (Mount, 1979; McGregor, 2002; Darcan et al., 2007; Bøe and Ehrlenbruch, 2013).

Inadequate temperatures, high humidity, and wind and rain are the main factors affecting thermal comfort in goats (McGregor, 2002; Bøe and Ehrlenbruch, 2013). Observation of respiratory rate can provide reliable and practical information for estimating the severity of heat stress in farm animals (Silanikove, 2000). A panting score has already been used for cattle (Gaughan, 2003) and it showed a predictive validity in goats (Darcan et al., 2007; Fioni, 2014). The score is assigned based on the visual observation of behavior, using a 5-point (Darcan et al., 2007) or a simplified 3-point (Fioni, 2014) scale. The 3-point score system proved sufficient to highlight a condition of thermal discomfort, such as in presence of severe heat stress situations, where goats showed signs ranging from accelerated respiration with mouth closed (score 1) to panting with open mouth and excessive salivation (score 2).

Although goats are frequently described as rustic or highly adaptable animals, research supports the fact that goats are negatively affected by low temperatures (McGregor, 2002; Bøe and Ehrlenbruch, 2013), to the extent that shivering sets in when they are exposed to low critical temperatures (Mount, 1979; Fioni, 2014). A feasible 3-point scale scoring system was developed and validated by Fioni (2014), who recorded signs of bristling hair on the back (score 1) and shivering with arched posture (score 2) related to severe cold stress.

Huddling is widely used by pigs to reduce heat loss at low temperatures (Andersen et al., 2000) but this strategy is not described in studies of natural populations of goats (Shackleton and Shank, 1984), although some farmers report anecdotal evidence of this behavior. Bøe and Ehrlenbruch (2013) recorded the lying behavior (lying alone vs. huddling) in 5 predefined weather conditions. Even though weather had a significant effect on huddling behavior, there was no clear evidence of its relation to decreasing temperatures.

Some physiological and blood parameters have been identified as valid indicators. Water intake, rumination rate, rectal temperature, pulse and respiration rate (Ogebe et al., 1996; Darcan et al., 2007), skin temperature (Darcan et al., 2007), glucose, total cholesterol, urea, and cortisol (Sejian and Srivastava, 2010) increase during heat stress situations. In contrast, total protein and aldosterone decrease under these conditions (Sejian and Srivastava, 2010). These indicators are not feasible, but they could be useful in future studies for validating indicators that are more practical for on-farm welfare assessment.

Some authors consider the time budget of general activity behaviors (e.g., feeding, lying, ruminating, drinking) as being related to thermal comfort (Bøe et al., 2007; Darcan et al., 2007; Table 3), because the effect of low or high environmental temperatures may affect behavioral patterns. Results from these authors confirmed that activity rhythms increase at low temperature and decrease at high temperature. In spite of their validity, the measurement of such behaviors is not recommended 
for on-farm use, as feasibility is hampered by the length of time required to compile the time budget.

\section{Ease of Movement}

By ease of movement, we mean the freedom of the animals to explore their surroundings without injuring themselves; in other words, "animals should have enough space to be able to move around freely" (Welfare Quality, 2009a), without risk of injury, at an adequate density. The animals have to be in sound enough condition to be able to walk, lie down, and stand up.

Anzuino et al. (2010) suggest that kneeling (at the trough) is a promising welfare indicator to assess discomfort due to inappropriate housing conditions. Kneeling behavior consists of goats dropping on their front knees. Anzuino et al. (2010) report that out of 24 UK farms, $79.2 \%$ showed goats kneeling (at the trough), but no correlation between lame and kneeling goats (at the trough) was found (Anzuino et al., 2010). This confirms that a badly designed feeding trough (e.g., floor-level bunk) may force both lame and sound goats to assume this position to reach the feed. The on-farm feasibility is presumably high for kneeling (at the trough) as this behavior is easily observed.

A standing-up score has been used by Mazurek et al. (2007) to detect problems in transition movement. The authors describe goats that stand up "lifting their back first" as animals with standing-up abnormalities. However, this behavior is commonly described as the normal standing-up transition movement for cattle (Albright and Arawe, 1997), and farmers and goat experts also consider it as the normal transition movement for goats; therefore, the standing-up score definition used by Mazurek et al. (2007) needs to be redefined. The main concern related to the feasibility of the standingup score is that the observer has to catch the precise instant when the transition movement starts. Therefore, observation of this indicator is closely linked to a specific moment, which lowers its on-farm feasibility.

Nordmann et al. (2011) used the duration of leaving the feed barrier to detect problems related to housing structure. This behavior was described as "the duration taken by the goats to leave the feed barriers. It began when a goat started to move its head with the intention to leave the feed barrier and finished just when the whole head of the goat (including nose) had left the feed barrier." Although this indicator has been validated, the feed barrier design may influence the behavior (Nordmann et al. 2011), and thus we consider it unfeasible in commercial farming conditions, as many goats are likely to leave the feed barrier at the same time, making the simultaneous direct observation of many animals very difficult.

\section{GOOD HEALTH PRINCIPLE}

Indicators related to health are the most quoted in our review because of the widespread availability of studies on this topic. All the reviewed indicators for this principle are presented in Table 4.

\section{Absence of Injuries}

According to this criterion, animals should be free from physical problems that may affect their health; for example, skin damage and locomotion disorders (Welfare Quality, 2009a).

Lameness is taken into consideration in several papers, as it is an important indicator of pain (O'Callaghan et al., 2003) and may lower productivity in dairy goats by reducing milk yield (Hill et al., 1997; Christodoulopoulos, 2009) and fertility (Hill et al., 1997; Eze, 2002; Christodoulopoulos, 2009), as well as contributing to pregnancy toxemia (Lima et al., 2012a) and neonatal diseases (Eze, 2002), and hence premature culling (Hill et al., 1997). The main causes of lameness in intensively kept dairy goats are claw overgrowth with or without deformation and diseases affecting the limb joints, such as caprine arthritis-encephalitis ( $\mathbf{C A E}$ ) and caprine contagious agalactia (Bergonier et al., 1997; Hill et al., 1997; Smith and Sherman, 2009; Winter, 2011). Lameness ranges from 9.1 to $24 \%$ in commercial farms (Hill et al., 1997; Eze, 2002; Mazurek et al., 2007; Christodoulopoulos, 2009). This large variation in prevalence of lameness can be due to various resources (e.g., access to pasture, indoor environment) and management practices (e.g., infrequent claw trimming), and especially to the fact that the authors assessed lameness using different methods and scales, and therefore the definition of clinical lameness in goats is unclear. Lameness scores have already been validated in some species (e.g., cattle: Thomsen et al., 2008; sheep: Winter, 2008), but there are no well-developed, established gait scoring systems in goats, so lameness is generally scored using different point scales (Hill et al., 1997; Mazurek et al., 2007; Anzuino et al., 2010) or by classifying goats as lame or sound (Christodoulopoulos, 2009). Hill et al. (1997) and Christodoulopoulos (2009) both showed evidence of a strong association between lameness and some of the foot lesions identified in their studies (hoof separation, abscess of the sole, footrot, interdigital dermatitis). However, none of these studies assessed reliability when using these scales, and hence, further studies are needed.

The location in which lameness assessment is performed varies: animals can be scored at the exit of the milking parlor (Anzuino et al., 2010) or in the group pen (Mazurek et al., 2007; Christodoulopoulos, 2009; 
INVITED REVIEW: INDICATORS FOR DAIRY GOAT WELFARE ASSESSMENT

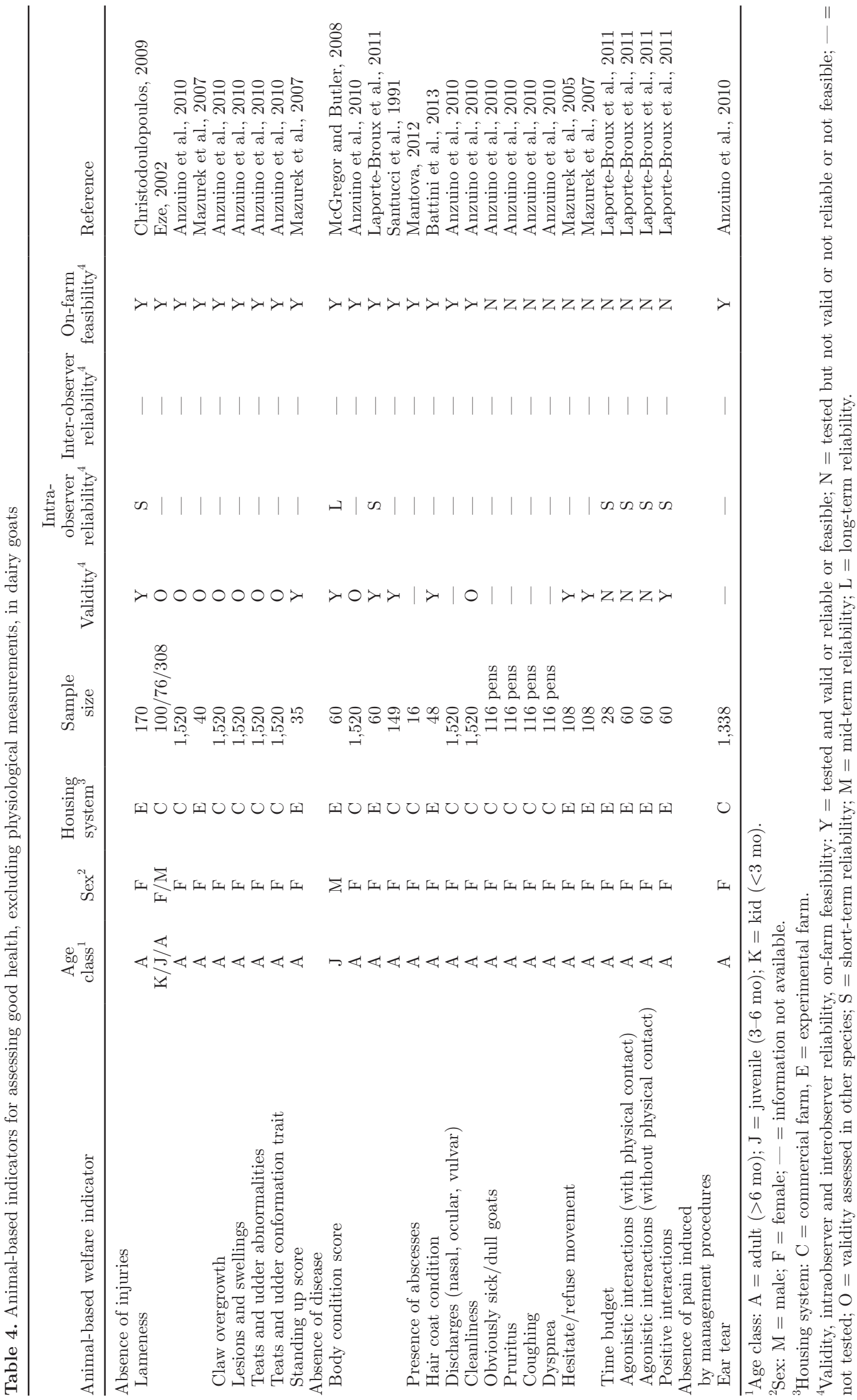


Anzuino et al., 2010). According to Anzuino et al. (2010), the prevalence of lameness estimated while the goats are in their pens is usually much lower than that observed when the goats exit the parlor. This may be because the observer can see the goats better when they are exiting the parlor or because the goats' locomotion is better when they walk on soft straw surfaces in their pens than when they walk on hard surfaces. This finding is important, because it suggests that assessing lameness in goats while they are housed in their pens may underestimate the severity and prevalence of the problem. However, if lameness is going to be assessed when goats are entering or exiting the milking parlor, a reliable sampling strategy should be planned, as the prevalence of lameness may depend on milking order. For example, in cows, a higher prevalence of lame animals has been observed in the last groups entering the milking parlor, compared with the first groups (Main et al., 2010). Furthermore, this not only highlights the importance of standardizing the location and type of flooring to perform lameness assessment in goat farms, but also the procedure for evaluating animals (e.g., how many strides) to obtain comparable results across different farms.

The sensitivity of the scoring system may vary across species. In goats, a maximum of 4 levels has been adopted by Anzuino et al. (2010), whereas in cattle scales up to 5 (e.g., Thomsen et al., 2008; Hoffman et al., 2014; Ito et al., 2014; Kougioumtzis et al., 2014) or 6 (e.g., Bell et al., 2009) levels have been used.

To make the scoring system more effective without reducing the on-farm feasibility, the drafting of a continuous lameness scale for individual goats would represent a significant advance in this field, such as the visual analog scale (VAS) recently established for cattle (Tuyttens et al., 2009). This modified scale has the advantage of enhancing sensitivity and, at the same time, producing continuous data that can be subjected to algebraic operations needed for aggregating the welfare indicators assessed in a protocol into a welfare index (Tuyttens et al., 2009). The reliability of this scoring system needs to be tested in goats.

Lameness is often correlated with claw overgrowth, which is a major problem in commercial dairy goat farms (Hill et al., 1997; Christodoulopoulos, 2009; Winter, 2011). In the UK, Anzuino et al. (2010) report that out of 1,520 sample animals, $79.8 \%$ had overgrown claws, and the problem was present at different levels of severity in all the farms surveyed. This high prevalence is probably due to a lack of hoof wear when animals are housed on straw bedding, or to poor management, such as an insufficient frequency of foot trimming (Hill et al., 1997; Eze, 2002; Anzuino et al., 2010). In dairy goats, claw overgrowth can be scored from moderate to severe, and a significant correlation with lameness has been demonstrated (Hill et al., 1997; Christodoulopoulos, 2009; Anzuino et al., 2010). The assessment of this indicator may be performed in the milking parlor and, if supported by an effective sampling strategy (similar to that reported for lameness; Main et al., 2010), can be feasible on farm.

The presence of lesions (including skin damages, swelling, and hair loss) is another possible indicator of poor health. Anzuino et al. (2010) observed that body and neck skin lesions are quite frequent (19.9 and $14.2 \%$ out of 1,520 goats, respectively), but they consist mainly of hair loss, whereas most of the lower limb skin lesions $(6.2 \%)$ consist of both skin damage and hair loss. Such lesions may not be painful but can still be important indicators of welfare, as they may reflect structure deficiencies (e.g., physical obstructions to normal behavior) or arise from trauma (e.g., hornless goats housed with horned goats; Aschwanden et al., 2008) or ectoparasites (Smith and Sherman, 2009).

In dairy animals, other possible animal-based indicators are lesions and abnormalities of teats and udders (Anzuino et al., 2010). In the same set of goats on UK farms mentioned above (Anzuino et al., 2010), teat and udder abnormalities in dairy goats were found with respective prevalences of 7.6 and $33.8 \%$, including lesions, wounds, inflammations, and accessory teats. Teat and udder lesions can affect both welfare and production in dairy goats (Perrin et al., 1997; Contreras et al., 2007; Leitner et al., 2008; Mavrogianni et al., 2011), but little published information describes the welfare significance and etiology of different lesions (Menzies and Ramanoon, 2001). Certain aspects of dairy goat farming, such as rapid milking rates, large herd size, high milk production, number of stockpersons, and minimal hygiene routine at milking, as well as some specific goat behavior, such as teat biting or self-sucking, may contribute to the development of teat and udder lesions (Stelwagen and Knight, 1997; Anzuino et al., 2010; Martínez-de la Puente et al., 2011; Torres et al., 2013). Evaluating teat and udder conformation traits may also be important for goat welfare. Research on dairy goats showed a relationship between pendulous udders and mastitis (Ameh et al., 1993; Deinhofer and Pernthaner, 1995), partly due to the increased risk of injury to the udder and teats when the distance between the teat ends and the floor is small. Udder asymmetry has been associated with chronic intramammary infection (e.g., CAE, contagious agalactiae, retroviral hard udder) causing induration and atrophy of one half (Krieg and Peterhans, 1990; Alawa et al., 2000; Paterna et al., 2013). Ameh et al. (1993) and Ameh and Tari (1999) found teat injuries to be associated with mastitis. This evidence supports the hypothesis 
that udder conformation is a risk factor for disease that may compromise dairy goat welfare and that a chronic change remains even after an udder has recovered from infection or injury (Krieg and Peterhans, 1990; Klaas et al., 2004; Smith and Sherman, 2009). Asymmetry and pendulous udders were recorded with prevalences of 22.0 and $5.3 \%$, respectively, out of 1,520 observed goats in UK farms (Anzuino et al., 2010) and 5.7 and $10.2 \%$, respectively, out of 423 goats in African breeds (Amao et al., 2003).

Teat and udder lesions, abnormalities, and conformation traits can easily be recorded by visual assessment from a short distance. The milking parlor is probably the best location in which to assess these indicators.

\section{Absence of Disease}

According to Welfare Quality (2009a), animals should be free from disease. Many indicators related to disease have never been validated in goat studies, but have been validated in cattle (as reviewed by Canali et al., 2009).

Body condition score is a valid and feasible indicator not only of the absence from prolonged hunger (as described and discussed for the good feeding principle), but also of the absence of disease. It is generally accepted that this indicator is important for identifying chronically ill goats; for example, BCS is decreased in the case of chronic contagious diseases, such as caseous lymphadenitis, paratuberculosis, or CAE, gastrointestinal parasitism, painful conditions (arthritis, footrot, laminitis), or in animals that have dental problems (Smith and Sherman, 2009; Mantova, 2012). In contrast, very thin or obese pregnant dairy goats risk pregnancy toxemia (Schlumbohm and Harmeyer, 2008; Brozos et al., 2011; Lima et al., 2012b), and BCS can therefore be successfully adopted to prevent the occurrence of this disease in periparturient goats (Laporte-Broux et al., 2011).

The presence of external abscesses is a common sign of pathology in goats. In most cases, external abscesses are located in lymph node areas (mainly mandibular, prescapular, prefemoral, and supramammary lymph nodes; Smith and Sherman, 2009). This external sign is often associated with caseous lymphadenitis caused by Corynebacterium pseudotuberculosis. This disease can also affect internal lymph nodes or organs, such as lungs, liver, or kidneys (Baird and Fontaine, 2007), but this form cannot be recorded by external examination and is not very common in goats (Smith and Sherman, 2009). The presence of abscesses maybe a valid and feasible animal-based indicator for on-farm welfare assessment, reflecting a general poor condition of the animal, as shown by reduced feeding time and low BCS recorded in goats with external abscesses (Mantova, 2012).

Hair coat condition can also be regarded as an interesting indicator to gather information not only on a goat's nutritional status (as already described and discussed for the good feeding principle), but also on its health status. In fact, recent research showed a higher prevalence of abnormal lung sounds (probably related to chronic respiratory disease) and a general condition of poor health in goats with rough and scurfy hair (Battini, 2013; Battini et al., 2013).

Kneeling has been already discussed according to the "ease of movement" criterion. Although the behavior is the same as that already described, Anzuino et al. (2010) distinguish between animals seen in kneeling posture at the trough and in the pen, as this behavior may assume different meanings. Kneeling (in the pen) consists of goats standing or walking on their front knees, without being involved in exploratory or feeding behavior. Such goats are generally not able to stand up and frequently reach the milking parlor or the feeding rack in this abnormal posture. The origin of this behavior is still unclear: the significant correlation recorded by Anzuino et al. (2010) between the prevalence of goats kneeling (in the pen) and of severely lame goats recorded when exiting the milking parlor suggests that kneeling behavior may be related to painful limb ailments. For example, kneeling is a common clinical sign in CAE and is frequent on infected farms (Adams et al., 1983; Smith and Sherman, 2009). The prevalence of farms with goats kneeling (in the pen) recorded by Anzuino et al. (2010) in the UK was extremely high ( $75 \%$ out of 24 farms), supporting the need for further investigation. The on-farm feasibility for kneeling (in the pen) as an indicator is high, as this behavior is not related to a specific moment and kneeling goats are quite easy to observe in the pen area.

Goats presenting discharges were recorded with low frequency on UK farms, where $5 \%$ of goats showed vulvar (mainly hemorrhagic), $0.6 \%$ nasal, and 6\% ocular discharges (Anzuino et al., 2010; see Table 4 for sample size). Discharges have already been included in cattle welfare assessment protocols (Canali et al., 2009). Their feasibility is accepted, but the best location to observe them needs to be identified, as the milking parlor only allows for the observation of vulvar discharges, whereas observations at the feeding rack allow only for the recording of those that are nasal and ocular.

We have already dealt with cleanliness as an indicator related to comfort around resting, and the feasibility of this indicator has already been discussed. In dairy cattle, udder cleanliness has been used as an indicator to assess the risk of mastitis (Hughes, 2001; Schreiner and Ruegg, 2003; Reneau et al., 2005), and is therefore 
considered related to health in this species. Studies are needed to understand if this indicator is valid as an assessment of health status in goats.

In accordance with the findings of Whay et al. (2003) in dairy cows in the UK $(1.6 \%$ of cows out of $20 \%$ of sampled animals in 53 herds), Anzuino et al. (2010) report a low herd prevalence of "obviously dull/sick goats" ( 1 or 2 goats per herd), but the authors do not provide an objective description of this indicator. Smith and Sherman (2009) use the terms "dull and listless" to define the behavior of goats with diseases such as chronic enterotoxemia, pregnancy toxemia, rumen impaction, and gastrointestinal parasitism. A more accurate and precise description of this term may be useful to facilitate the identification of these goats in the herd and increase the reliability of the indicator. Farmers and technicians report that sick goats try to isolate themselves from the group and they generally stand immobile, sometimes facing the wall or other parts of the housing structure. Although deriving from anecdotal information, this description is clear and could form the basis for an accurate definition of "obviously dull/ sick goats." The presence of this behavioral phenotype might be a promising indicator for pinpointing animals in poor health in a herd-living, gregarious species such as goats (Miranda-de la Lama and Mattiello, 2010). Therefore, the presence of isolated individuals may be interesting as an early-warning indicator of health problems, but it needs to be well defined and tested for validity and on-farm feasibility.

Laporte-Broux et al. (2011) considered different general activity behaviors (e.g., standing, feeding), aggressive interactions (e.g., threat, chase), and positive interactions (e.g., grooming) that may be influenced and altered by the presence of diseases, such as induced pregnancy toxemia. The validity of some of these behaviors has been assessed, as goats with pregnancy toxemia due to restricted diet increase feed searching and related active behaviors (e.g., walking, exploratory behaviors) but decrease positive interactions. The validity of behavior for predicting diseases has already been confirmed in other ruminant species, such as cattle, where the time spent feeding and the frequency of visits to the feeder are significantly reduced by severe metritis (Huzzey et al., 2007) or ketosis (Goldhawk et al., 2009). The feasibility of these indicators remains an issue if the time budget needs to be recorded.

In dairy animals, SCC is an important milk characteristic possibly related to animal welfare. Research in dairy goats suggests that this indicator is related to intramammary infections, as SCC increases in presence of clinical or subclinical mastitis (Paape et al., 2007; Koop et al., 2012), although the latter is asymptomatic and is not reported to affect goat welfare (Jimenez-Granado et al., 2014). Somatic cell count is routinely collected herd data on bulk milk; therefore, it is available in most farms. However, it lacks sensitivity, because it can be affected by several factors, such as parity, lactation stage, and milk yield (Koop et al., 2013), that may increase SCC even in the absence of udder infection. To our knowledge, no appropriate statistical models are available to correct for all named factors in goat bulk milk to date.

\section{Absence of Pain Induced by Management Procedures}

This welfare criterion is related to the statement that "animals should not suffer pain induced by inappropriate management, handling, slaughter, or surgical procedures (e.g. castration, dehorning)" (Welfare Quality, 2009a).

One common management practice that may have a negative effect on the welfare of adult dairy goats is ear tagging. If tags are not correctly placed through the center of the ear, inflammation or ear tear (Smith and Sherman, 2009; Anzuino et al., 2010) may occur, causing moderate pain. The prevalence of ear tear recorded by Anzuino et al. (2010) was $6.2 \%$ of goats (out of 1,520 goats). To our knowledge, these are the only data available on the damage associated with ear tagging in goats. In-depth studies on this potential indicator are needed, as it seems a promising inclusion for on-farm welfare protocol.

Routine trimming is a required management procedure, essential to maintain normal hoof structure (Smith and Sherman, 2009). This procedure should be carried out at least twice a year due to the fact that on intensive farms, the limited movement of goats may alter the normal growth of the hoof, leading to claw overgrowth. Welfare problems associated with overgrown claws are widely explained in "absence of injuries" criterion. However, if trimming is not correctly performed, it may cause pain or expose inner tissue to trauma and infection (Nagy and Pugh, 2012).

Other procedures that may have a negative effect on goat welfare are improper disbudding (incomplete burn of the horn bud through the skin) and dehorning. Presence of horns or trace of horns in adult goats due to previous improper disbudding when they were kids may be a welfare issue. Scurs can press against the head or eye, causing lesions and pain (Smith and Sherman, 2009) and they have been associated with adverse sequelae, such as sinusitis, brain abscesses, or tetanus (Smith and Sherman, 2009; Plummer and Schleining, 2013). Farmers also report that scurs may get caught in fences and pen partitions. Furthermore, horned or partially horned goats may adopt agonistic 
behavior, causing lesions and possible social stress to other goats (Waiblinger et al., 2011). For this reason, mixed groups of horned and hornless goats should be carefully managed by farmers, thus good practices are required (e.g., group stability, space allowance). Signs that adult animals have been dehorned or have traces of horns due to improper disbudding are clearly visible on farm, especially when goats are at the feed trough; thus, improper disbudding may be a suitable indicator to be adopted on farm.

\section{APPROPRIATE BEHAVIOR PRINCIPLE}

The "appropriate behavior" principle is related to the opportunity that goats have to express social and species-specific behaviors and also to their relationships with humans. All indicators for the welfare criteria included in this principle are presented in Table 5 .

\section{Expression of Social Behaviors}

In gregarious animals such as goats, that are usually housed in group pens, social behavior is very important, and the possibility to "express a normal, non-harmful, social behavior (e.g., allo-grooming)" (Welfare Quality, 2009a) should always be guaranteed.

Social behavior can be altered by management procedures (e.g., regrouping; Miranda-de la Lama and Mattiello, 2010) or housing conditions (e.g., stocking density: Van et al., 2007; lack of resources such as feed: Loretz et al., 2004; Jørgensen et al., 2007; Laporte-Broux et al., 2011; water: Ehrlenbruch et al., 2010b; lying space: Loretz et al., 2004; Andersen and Bøe, 2007).

Agonistic behavior has 2 main aims: resource achievement and dominance establishment (Shackleton and Shank, 1984), but the increase of these interactions is considered as a negative expression of social behavior in cattle (Laister et al., 2009). Compared with other female ungulates, goats are reported to have a significantly higher rate of aggressive interactions (Fournier and Festa-Bianchet, 1995). The validity of agonistic behavior as an indicator has been confirmed in many papers. In fact, the increase of agonistic behavior is commonly related to the decreased size of the resting area (Andersen and Bøe, 2007; Van et al., 2007; Aschwanden et al., 2009a), to regrouping (Fernandez et al., 2007; Andersen et al., 2008), or to insufficient resource availability (e.g., scarce number of feeding or water places: Ehrlenbruch et al., 2010b). Fernandez et al. (2007) even found a decrease in milk production in goats subjected to regrouping: it is known that regrouping may lead to an enhancement of aggressive interaction, thus increasing stress. Stress plays a fundamental role in reducing milk yield, as reported in cows (Varner and Johnson, 1983; Shamay et al., 2000); therefore, a concurrent validity is confirmed for agonistic interaction. Feasibility is questionable; observation usually requires a prolonged period of time to obtain reliable information (Nordmann et al., 2011). Among agonistic behaviors (e.g., threats, frontal clashes, chases, butts, displacements), the most feasible is displacement, as already described in this review for "absence of prolonged hunger and prolonged thirst" criteria (Table 2).

Queuing at the feed barrier has been already described for assessing the "absence of prolonged hunger" criterion, as well as the effect of queuing on nutritional deficiencies and frustration in dairy goats. However, queuing at the feed barrier may also be used to evaluate the quality of social interactions, as confirmed by Jørgensen et al. (2007), who found that low-status goats spent more time queuing than high-status goats, demonstrating that competitive environments are a welfare issue for subordinate animals rather than for dominants. The validity of queuing at the drinker as an indicator of social behavior has not been tested (Ehrlenbruch et al., 2010b), but it is assumed that results similar to queuing at the feed barrier may occur when the ratio of nipples to goats is inadequate, as found for the "absence of prolonged thirst" criterion.

Vocalizations may be an interesting indicator of welfare in farm animals (e.g., pigs and cattle; Manteuffel et al., 2004), and some authors report the use of vocalizations to assess the quality of social behavior in goats (Mazurek et al., 2005, 2007; Siebert et al., 2011). However, specific studies need to be conducted to gather more information about the motivation of goats to vocalize. For example, increased vocal responses in situations of social isolation can be interpreted either as an adaptive and active attempt to communicate with companions or as a sign of distress and fear (Siebert et al., 2011). Moreover, the mere verbal description of sounds is incomplete and misleading as it lacks loudness, duration, and frequency traits (Manteuffel et al., 2004); therefore, specific instruments for recording (e.g., digital signal processing; Siebert et al., 2011) and analyzing sounds (e.g., digital sonograms bio-acoustical analyses; Manteuffel et al., 2004) are required and, thus, the feasibility of this indicator is compromised.

\section{Expression of Other Behaviors}

Other behaviors include the possibility "to express species-specific natural behaviors such as foraging" (Welfare Quality, 2009a). If animals cannot meet their natural needs and cannot perform their entire behavioral repertoire, they may experience a negative affective state. However, no feasible indicator of absence of natural behaviors has been identified so far. Therefore, 


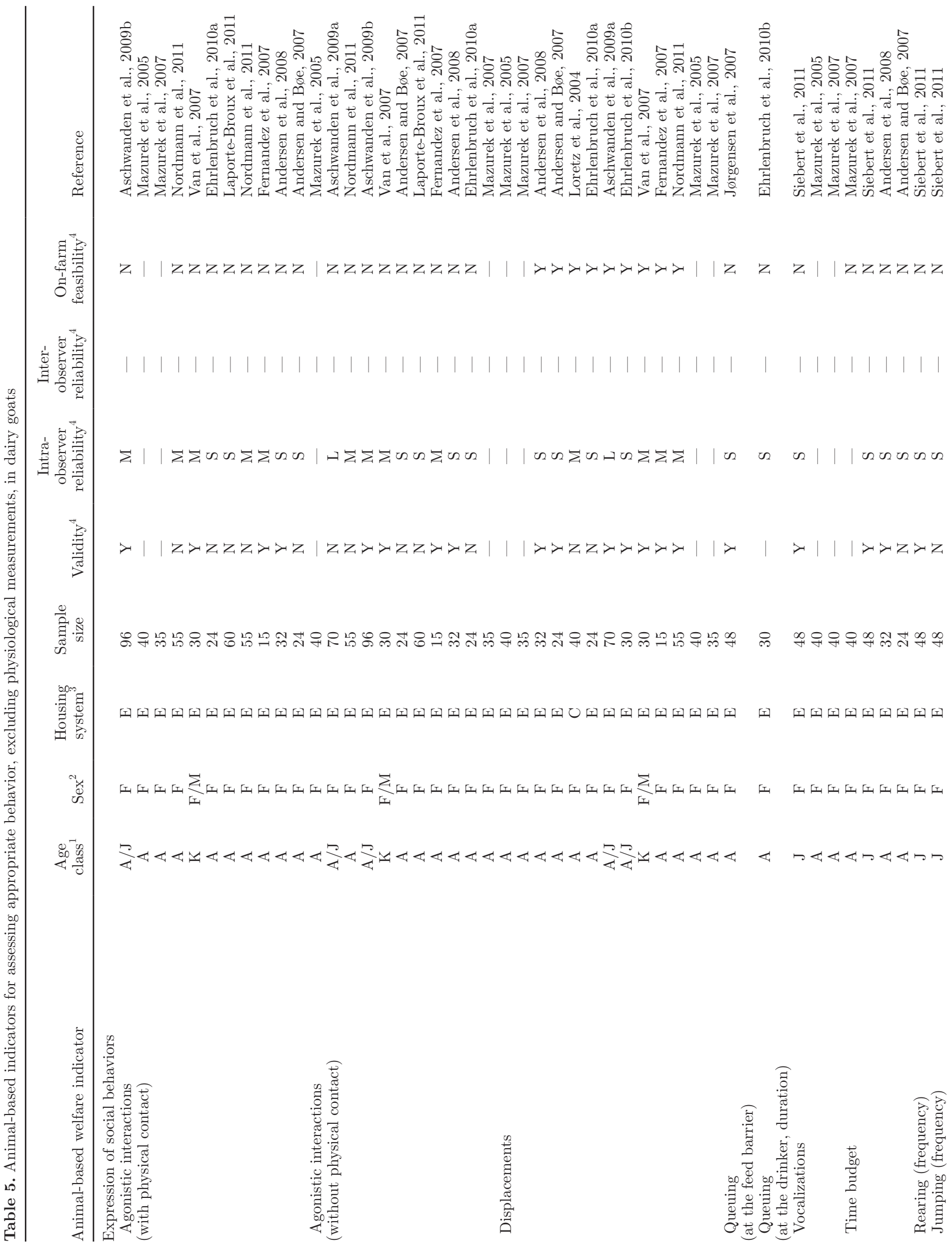




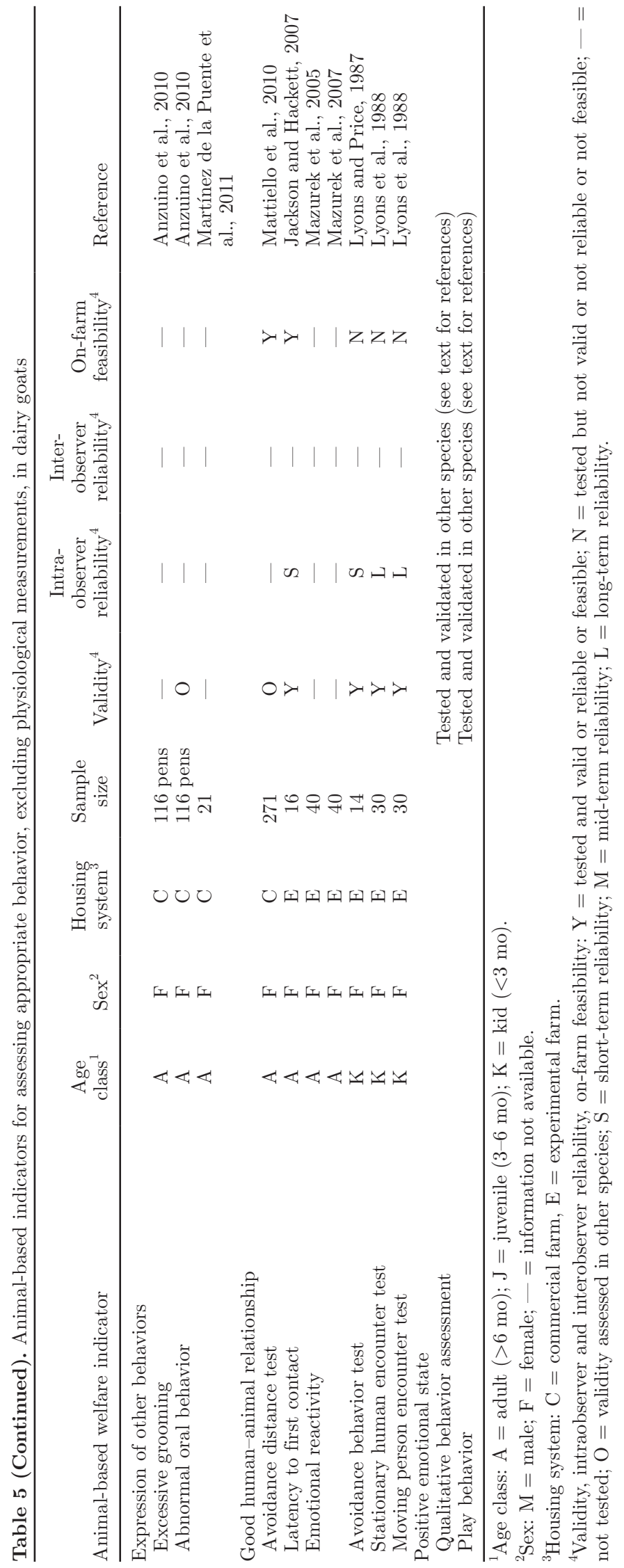

in this section, we will only consider as indicators of negative affective state the presence of behaviors that are not species-specific under natural conditions or that are performed with unnatural frequency. Excessive scratching or rubbing (pruritus) and abnormal oral behavior can be considered as promising indicators of a poor welfare condition (Mason and Rushen, 2006). Several studies are available to support the observation of these behaviors as welfare indicators in many species (e.g., pigs: Brunberg et al., 2011; cattle: Mattiello et al., 2002; Kamboj et al., 2007). In goats, Anzuino et al. (2010) reported that $91.7 \%$ out of 24 UK farms had goats affected by pruritus, and the validity of this indicator seems to be supported by the positive correlation with the prevalence of body skin lesions.

Behaviors such as oral manipulation of inert objects are potential welfare issues requiring further investigation. Lack of roughage and concentrate feed was associated with abnormal oral behavior in goat kids (Mattiello et al., 2008). According to Anzuino et al. (2010), abnormal oral behaviors in goats are mainly directed at the bars (found in $91.7 \%$ out of 24 farms) or walls of pen structures (83.3\% of farms). Self-suckling and inter-suckling are also abnormal oral behaviors common among certain goat breeds (e.g., Murciana) and farms (Griffioen, 2012). As reported by Martínezde la Puente et al. (2011) in the Majorera breed, selfsuckling has been shown to be reduced when extra fiber is added to the ordinary diet (composed of corn, soy, dehydrated lucerne, dehydrated beetroot, lucerne hay, vitamin-mineral supplement) and distributed twice a day. The authors of this study suggest that by having ad libitum access to wheat straw, goats ruminate more and thus satisfy their oral behavioral needs. The main issue related to the recording of these behaviors is the fact that direct observation requires not only a long observation period, but also an accurate choice of observation time (i.e., just before feeding time). In addition, abnormal behaviors can be difficult to record in large groups (Anzuino et al., 2010), especially in the absence of an adequate sampling strategy.

\section{Good Human-Animal Relationship}

This criterion is based on the assumption that "Animals should be handled well in all situations, i.e. handlers should promote good human-animal relationships" (Welfare Quality, 2009a).

Many published studies provide proof of the effect of stockmanship on animal production (e.g., Hemsworth and Barnett, 1991; Lensink et al., 2001; Hemsworth, 2003) and welfare (e.g., Rousing and Waiblinger, 2004; de Passillé and Rushen, 2005). Nevertheless, the effect of the quality of human-animal relationships on pro- 
ductive traits and welfare has rarely been investigated in goats. The human-animal relationship tests enable us to gain information about the level of fear as a consequence of the quality and frequency of the previous human-animal interactions (Waiblinger et al., 2006). The promising tests identified so far belong to 2 main categories: reaction to a stationary person and reaction to a moving person. The latency to approach a stationary person test, already used in cattle by several authors (Jago et al., 1999; Breuer et al., 2000; Hemsworth et al., 2000; Lensink et al., 2000), was applied by Jackson and Hackett (2007) to evaluate the positive effect of gentle handling treatment in goats. The research showed that animals approached a person more quickly if they had already experienced positive contact with humans (Jackson and Hackett, 2007). The avoidance distance test to a moving person developed for cattle (Windschnurer et al., 2009) was validated in goats by Mattiello et al. (2010), who confirmed its validity to detect different avoidance reactions of goats depending on farm size and, consequently, on management practices. Behavioral tests for assessing the human-animal relationship seem to be valid, feasible, and reliable in several species (sheep: Napolitano et al., 2011; beef heifers: Mazurek et al., 2011; buffalos: de Rosa et al., 2005; dairy cows: Rousing and Waiblinger, 2004). However, they require time and training and might induce stress in the animals. For example, Muri et al. (2013) reported strong avoidance behavior and goats flocking around when the observer tried to perform the avoidance distance test. The development of less intrusive and time-consuming, but still valid, indicators would be useful. Farmers have suggested other possible indicators, such as alert calls, but no scientific evidence is available to support their use in assessing the quality of human-animal relationship in goats.

\section{Positive Emotional State}

This last criterion is very difficult to assess, and it is based on the concept that "Negative emotions such as fear, distress, frustration or apathy should be avoided whereas positive emotions such as security or contentment should be promoted" (Welfare Quality, 2009a).

Most welfare indicators focus on negative aspects, whereas positive emotional state is not taken into consideration very often. Play behavior is one of the few positive indicators in the existing literature on farm animals (calves: Jensen and Kyhin, 2000; pigs: Reimert et al., 2013); however, this is seldom expressed by adult ruminants and it is too time consuming to record (Napolitano et al., 2009). New indicators need to be developed to detect positive emotional states. Currently, one promising approach is the qualitative behavior assessment, which consists of a whole-animal approach in which the observer can integrate perceived behavioral details and signals to judge an animal's behavioral expression, using qualitative descriptors (e.g., content, relaxed, anxious) that reflect the animal's emotional state (Wemelsfelder, 2007). Studies on many species, such as horses (Minero et al., 2009), pigs (Wemelsfelder et al., 2009; Rutherford et al., 2012), and sheep (Phythian et al., 2013), have shown that data generated from such observations is reliable and repeatable, and it correlates with animal behavior observed by traditional quantitative methods. So far, no information has been made available on the use of qualitative behavior assessment in goats. Research on this topic is worth pursuing.

\section{SUMMARY AND CONCLUSIONS}

This review aimed to highlight goat welfare indicators that may be suitable for on-farm welfare assessment. Validity, reliability, and feasibility were the major attributes taken into account. According to these attributes, few indicators can be considered promising and all require further adjustment or research. Furthermore, not all the principles and criteria addressed in this review are covered by the indicators available to date. As can be expected, indicators related to injuries and diseases are the most studied, whereas those related to other principles need further investigation. Health indicators were attributed more attention due to their economic relevance. Similarly, many indicators have been found to evaluate "absence of prolonged hunger," whereas few animal-based indicators have been developed for onfarm assessment of "absence of prolonged thirst," possibly because they are easily replaced by resource-based parameters (e.g., number of drinkers/animal and water flow). The most promising indicators are summarized in Table 6. In line with the present state of the art, no indicator can be included in an on-farm welfare assessment protocol as it stands. Each one of the potential indicators needs to be adjusted or further refined in terms of validity, reliability, or feasibility. For example, interobserver reliability has seldom been assessed and further studies are needed: concordance among observers is essential when setting up reliable data collection. Easy-to-perform observations or simplified point scales are recommended for obtaining high interobserver agreement but, in any case, rigorous training is required. In contrast, short-term intraobserver reliability has frequently been assessed, and some studies also consider mid- and long-term reliability. This issue is very important, as the consistency of indicators over time is crucial in welfare assessment protocols that need to be used at any time. From a methodological 
Table 6. Promising indicators identified as suitable for inclusion in on-farm welfare assessment protocol, classified according to Welfare Quality principles and criteria

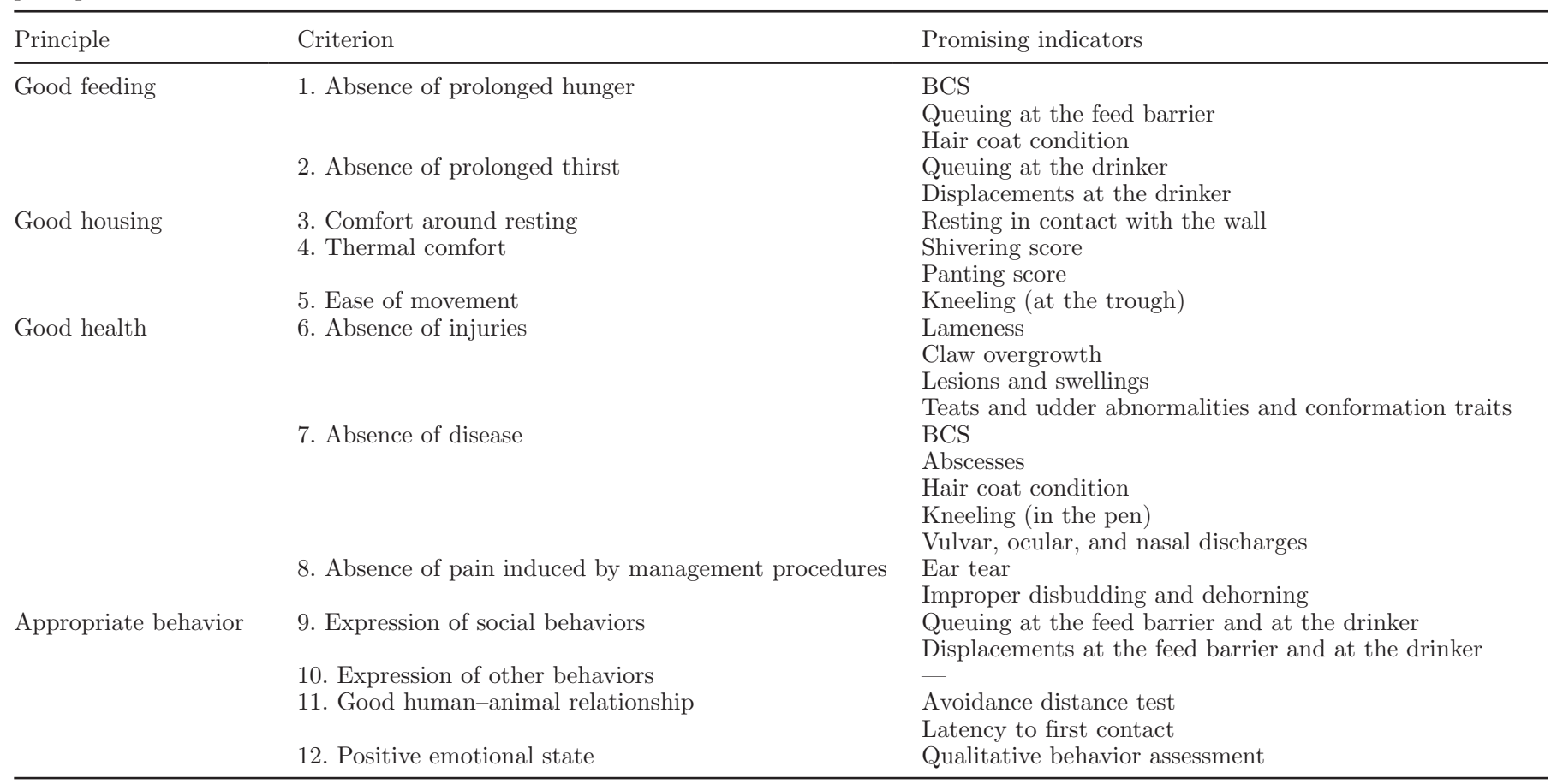

point of view, most of the studies carried out so far have been performed under experimental conditions, so the feasibility on commercial farms of the indicators adopted in these studies needs to be carefully evaluated. Our list of promising indicators took this issue into account, highlighting the need for further studies for on-farm feasibility.

Another issue related to feasibility is that the recording of behavior is generally time consuming. Most of the behavioral indicators reviewed in this paper were collected by video-recording, not by direct observation. This makes them unsuitable for inclusion in a practical on-farm welfare assessment protocol, unless we find alternative ways to collect the data. This is why we have continually emphasized the idea of applying an effective sampling strategy to record data on-farm. It is important to underline that some indicators, such as BCS, hair coat condition, and queuing, can be applied to different criteria. These indicators warrant particular attention, as they could be very useful to save time, by providing information about several welfare aspects. Existing welfare assessment protocols usually highlight negative aspects, and most of the reviewed indicators are actually focused on welfare problems, such as presence of lesions, lameness, diseases, abnormal behavior, or poor body condition. However, positive indicators deserve further attention and their inclusion should be fostered, as they may play a key role in the communication of animal welfare to the stakeholders.
The aim of this review was to act as a starting point in the identification of animal-based indicators in dairy goats. Further studies are needed to bridge the gaps highlighted by the present review, to confirm the already existing results, and to develop a complete and effective on-farm welfare assessment protocol for dairy goats. Such a protocol may then be used as a basis for developing specific protocols for other categories, such as kids and bucks, and for different production systems (e.g., meat and fiber) and extensive husbandry that may have specific welfare problems not addressed in this review.

\section{ACKNOWLEDGMENTS}

The authors thank the EU VII Framework program (FP7-KBBE-2010-4) for financing the Animal Welfare Indicators (AWIN) project. We also acknowledge all of the experts involved for their extensive contribution and valuable support and the assistance of Kirk T. Ford for the revision of the English manuscript. Finally, we thank the two anonymous reviewers whose encouraging and enthusiastic comments greatly helped to improve the manuscript.

\section{REFERENCES}

Acock, A. C. 2008. A Gentle Introduction to Stata. Stata Press, College Station, TX. 
Adams, D. S., P. Klevjer-Anderson, J. L. Carlson, T. C. McGuire, and J. R. Gorham. 1983. Transmission and control of caprine arthritisencephalitis virus. Am. J. Vet. Res. 44:1670-1675.

Al-Ramamneh, D., A. Riek, and M. Gerken. 2012. Effect of water restriction on drinking behaviour and water intake in German blackhead mutton sheep and Boer goats. Animal 6:173-178.

Alawa, J. P., M. B. Ngele, and D. Ogwu. 2000. Chronic caprine mastitis in Nigerian goat breeds; microbiological flora and histopathological findings. Small Rumin. Res. 35:203-207.

Albright, J., and C. Arawe. 1997. The Behaviour of Cattle. CAB International, Wallingford, UK.

Amao, O. A., O. A. Osinowo, C. A. M. Lakpini, M. A. Dipeolu, S. S. Abiola, and C. F. I. Onwuka. 2003. Types and frequency of udder shapes and abnormalities in West African Dwarf and Red Sokoto goats. Nigerian J. Anim. Prod. 30:246-252. http://dx.doi. org/10.4314/njap.v30i2.3303.

Ameh, J. A., P. B. Addo, J. O. Adekeye, and E. O. Gyang. 1993. Prevalence of clinical mastitis and of intramammary infections in Nigerian goats. Prev. Vet. Med. 17:41-46.

Ameh, J. A., and I. S. Tari. 1999. Observations on the prevalence of caprine mastitis in relation to predisposing factors in Maiduguri. Small Rumin. Res. 35:1-5.

Andersen, I. L., and K. E. Bøe. 2007. Resting pattern and social interactions in goats - The impact of size and organisation of lying space. Appl. Anim. Behav. Sci. 108:89-103.

Andersen, I. L., K. E. Bøe, and K. Hove. 2000. Behavioral and physiological thermoregulation in groups of pregnant sows housed in a kennel system at low temperatures. Can. J. Anim. Sci. 80:1-8.

Andersen, I. L., S. Roussel, E. Ropstad, B. O. Braastad, G. Steinheim A. M. Janczak, G. H. M. Jørgensen, and K. E. Bøe. 2008. Social instability increases aggression in groups of dairy goats, but with minor consequences for the goats' growth, kid production and development. Appl. Anim. Behav. Sci. 114:132-148.

Andreasen, S. N., and B. Forkman. 2012. The welfare of dairy cows is improved in relation to cleanliness and integument alterations on the hocks and lameness when sand is used as stall surface. J. Dairy Sci. 95:4961-4967. http://dx.doi.org/10.3168/jds.20115169.

Anzuino, K., N. J. Bell, K. J. Bazeley, and C. J. Nicol. 2010. Assessment of welfare on 24 commercial UK dairy goat farms based on direct observations. Vet. Rec. 167:774-780.

Aschwanden, J., L. Gygax, B. Wechsler, and N. M. Keil. 2008. Social distances of goats at the feeding rack: Influence of the quality of social bonds, rank differences, grouping age and presence of horns. Appl. Anim. Behav. Sci. 114:116-131.

Aschwanden, J., L. Gygax, B. Wechsler, and N. M. Keil. 2009a. Structural modifications at the feeding place: Effects of partitions and platforms on feeding and social behaviour of goats. Appl. Anim. Behav. Sci. 119:180-192.

Aschwanden, J., L. Gygax, B. Wechsler, and N. M. Keil. 2009b. Loose housing of small goat groups: Influence of visual cover and elevated levels on feeding, resting and agonistic behavior. Appl. Anim. Behav. Sci. 119:171-179.

Baird, G. J., and M. C. Fontaine. 2007. Corynebacterium pseudotuberculosis and its role in ovine caseous lymphadenitis. J. Comp. Pathol. 137:179-210.

Bartussek, H. 1999. A review of the Animal Needs Index (ANI) for the assessment of animals' well-being in the Housing Systems for Austrian proprietary products and legislation. Livest. Prod. Sci. 61:179-192.

Battini, M. 2013.Animal-based indicators for on-farm welfare assessment in cattle and goats. PhD Thesis. University of Milan, Milan, Italy.

Battini, M., L. Grosso, S. Barbieri, I. Ajuda, A. Vieira, G. T. Stilwell, and S. Mattiello. 2013. Le condizioni del mantello sono un valido indicatore di benessere nella capra? Large Anim. Rev. 5(Suppl. $1): 10$.

Bell, N. J., M. J. Bell, T. G. Knowles, H. R. Whay, D. C. J. Main, and A. J. F. Webster. 2009. The development, implementation and testing of a lameness control programme based on HACCP principles and designed for heifers on dairy farms. Vet. J. 180:178-188.
Bergonier, D., X. Berthelot, and F. Poumarat. 1997. Contagious agalactia of small ruminants: Current knowledge concerning epidemiology, diagnosis and control. Rev. Sci. Tech. 16:848-873.

Blokhuis, H. J., M. Miele, I. Veissier, and R. B. Jones. 2013. Improving farm animal welfare. Science and Society Working Together: The Welfare Quality Approach. Wageningen Academic Publishers, Wageningen, the Netherlands.

Blokhuis, H. J., I. Veissier, M. Miele, and B. Jones. 2010. The Welfare Quality ${ }^{\circledR}$ project and beyond: Safeguarding farm animal wellbeing. Acta Agric. Scand. Anim. Sci. 60:129-140. http://dx.doi. org $/ 10.1080 / 09064702.2010 .523480$.

Bøe, K. E., I. L. Andersen, L. Buisson, E. Simensen, and W. K. Jeksrud. 2007. Flooring preferences in dairy goats at moderate and low ambient temperature. Appl. Anim. Behav. Sci. 108:45-57.

Bøe, K. E., S. Berg, and I. L. Andersen. 2006. Resting behaviour and displacements in ewes-Effects of reduced lying space and pen shape. Appl. Anim. Behav. Sci. 98:249-259.

Bøe, K. E., and R. Ehrlenbruch. 2013. Thermoregulatory behavior of dairy goats at low temperatures and the use of outdoor yards. Can. J. Anim. Sci. 93:35-41.

Brambell Committee. 1965. Report of the Technical Committee to Enquire into the Welfare of Animals Kept under Intensive Livestock Husbandry Systems. Command Report 2836. Her Majesty's Stationery Office, London, UK.

Braun, U., T. Rihs, and U. Schefer. 1992. Ruminal lactic acidosis in sheep and goats. Vet. Rec. 130:343-349.

Breuer, K., P. H. Hemsworth, J. L. Barnett, L. R. Matthews, and G. J. Coleman. 2000. Behavioural response to humans and the productivity of commercial dairy cows. Appl. Anim. Behav. Sci. $66: 273-288$.

Brozos, C., V. S. Mavrogianni, and G. C. Fthenakis. 2011. Treatment and control of peri-parturient metabolic diseases: Pregnancy toxemia, hypocalcemia, hypomagnesemia. Vet. Clin. North Am. Food Anim. Pract. 27:105-113.

Brunberg, E., A. Wallenbeck, and L. J. Keeling. 2011. Tail biting in fattening pigs: Associations between frequency of tail biting and other abnormal behaviours. Appl. Anim. Behav. Sci. 133:18-25.

Canali, E., H. R. Whay, and K. A. Leach. 2009. Cattle health status. Pages 77-88 in Welfare Quality ${ }^{\circledR}$ Report No. 11-Assessment of Animal Welfare Measures for Dairy Cattle, Beef Bulls and Veal Calves. B. Forkman and L. Keeling, ed. Cardiff University, Cardiff, UK.

Carbonaro, D. A., T. H. Friend, and G. R. Dellmeier. 1992. Behavioral and physiological responses of dairy goats to food thwarting. Physiol. Behav. 51:303-308. http://dx.doi.org/10.1016/00319384(92)90145-R

Caroprese, M., D. Casamassima, S. P. G. Rassu, F. Napolitano, and A. Sevi. 2009. Monitoring the on-farm welfare of sheep and goats. Ital. J. Anim. Sci. 8:343-354.

Christodoulopoulos, G. 2009. Foot lameness in dairy goats. Res. Vet. Sci. 86:281-284.

Contreras, A., D. Sierra, A. Sanchez, J. C. Corrales, J. C. Marco, M. J Paape, and C. Gonzalo. 2007. Mastitis in small ruminants. Small Rumin. Res. 68:145-153.

Cornetto, T. L., and I. Estevez. 2001. Influence of vertical panels on the use of space by domestic fowl. Appl. Anim. Behav. Sci. $71: 141-153$.

Darcan, N., F. Cedden, and S. Cankaya. 2007. Spraying effects on some physiological and behavioural traits of goats in a subtropical climate. Ital. J. Anim. Sci. 7:77-85.

de Passillé, A. M., and J. Rushen. 2005. Can we measure humananimal interactions in on-farm animal welfare assessment? Some unresolved issues. Appl. Anim. Behav. Sci. 92:193-209. http:// dx.doi.org/10.1016/j.applanim.2005.05.006.

de Rosa, G., F. Grasso, C. Pacelli, F. Napolitano, and C. Winckler 2009. The welfare of dairy buffalo. Ital. J. Anim. Sci. 8:103-116.

de Rosa, G., F. Napolitano, F. Grasso, C. Pacelli, and A. Bordi. 2005 On the development of a monitoring scheme of buffalo welfare at farm level. Ital. J. Anim. Sci. 4:115-125.

de Vries, M., E. A. M. Bokkers, G. van Schaik, B. Engel, T. Dijkstra, and I. J. M. de Boer. 2014. Exploring the value of routinely col- 
lected herd data for estimating dairy cattle welfare. J. Dairy Sci. 97:715-730. http://dx.doi.org/10.3168/jds.2013-6585.

Deinhofer, M., and A. Pernthaner. 1995. Staphylococcus spp. as mastitis-related pathogens in goat milk. Vet. Microbiol. 43:161-166.

Desnoyers, M., G. Béchet, C. Duvaux-Ponter, P. Morand-Fehr, and S. Giger-Reverdin. 2009. Comparison of video recording and a portable electronic device for measuring the feeding behaviour of individually housed dairy goats. Small Rumin. Res. 83:58-63. http:// dx.doi.org/10.1016/j.smallrumres.2009.04.003.

EFSA. 2012. Statement on the use of animal-based measures to assess the welfare of animals. Panel on Animal Health and Welfare (AHAW). EFSA J. 10:2767 10.2903/j.efsa.2012.2767.

Ehrlenbruch, R., G. H. M. Jørgensen, I. L. Andersen, and K. E. Bøe. 2010a. Provision of additional walls in the resting area-The effects on resting behaviour and social interactions in goats. Appl. Anim. Behav. Sci. 122:35-40.

Ehrlenbruch, R., T. Pollen, I. L. Andersen, and K. E. Bøe. 2010b. Competition for water at feeding time - The effect of increasing number of individuals per water dispenser. Appl. Anim. Behav. Sci. 126:105-108.

Eze, C. A. 2002. Technical note: Lameness and reproductive performance in small ruminants in Nsukka Area of the Enugu State, Nigeria. Small Rumin. Res. 44:263-267.

Færevik, G., I. L. Andersen, and K. E. Bøe. 2005. Preferences of sheep for different types of pen flooring. Appl. Anim. Behav. Sci. 90:265-276.

Fernandez, M. A., L. Alvarez, and L. Zarco. 2007. Regrouping in lactating goats increases aggression and decreases milk production. Small Rumin. Res. 70:228-232.

Ferreira, L. M. M., R. Celaya, R. Benavides, B. M. Jáuregui, U. García, A. S. Santos, R. R. García, M. A. M. Rodrigues, and K. Osoro. 2013. Foraging behaviour of domestic herbivore species grazing on heathlands associated with improved pasture areas. Livest. Sci. 155:373-383

Fioni, L. 2014. Validazione di indicatori di comfort termico per la valutazione del benessere negli allevamenti caprini da latte. BSc Thesis. University of Milan, Milan, Italy.

Forkman, B. 1996. The social facilitation of drinking: What is facilitated, and who is affected? Ethology 102:252-258.

Fournier, F., and M. Festa-Bianchet. 1995. Social dominance in adult female mountain goats. Anim. Behav. 49:1449-1459.

Gaughan, J. B. 2003. Using panting scores to assess heat load in cattle. Interactions between climate and animal production. EAAP Technical Series 7:99-107. EAAP, Rome, Italy.

Goldhawk, C., N. Chapinal, D. M. Veira, D. M. Weary, and M. A. G. von Keyserlingk. 2009. Prepartum feeding behavior is an early indicator of subclinical ketosis. J. Dairy Sci. 92:4971-4977. http:// dx.doi.org/10.3168/jds.2009-2242.

Görgülü, M., M. Boğa, A. Şahin, U. Serbester, H. R. Kutlu, and S. Şahinler. 2008. Diet selection and eating behaviour of lactating goats subjected to time restricted feeding in choice and single feeding system. Small Rumin. Res. 78:41-47.

Griffioen, J. K. D. H. M. 2012. Does self-sucking in dairy goats develop in the raising period? $\mathrm{PhD}$ Thesis. Utrecht University, Utrecht, the Netherlands. http://dspace.library.uu.nl/bitstream/ handle/1874/240726/Onderzoeksverslag\%20Cors\%20Griffioen. docx? sequence $=1$.

Grove-White, D. 2004. Rumen health care in the dairy cow. In Pract. 26:88-95.

Hemsworth, P. 2003. Human-animal interaction in livestock production. Appl. Anim. Behav. Sci. 81:185-198.

Hemsworth, P. H., and J. L. Barnett. 1991. The effects of aversively handling pigs, either individually or in groups, on their behaviour, growth and corticosteroids. Appl. Anim. Behav. Sci. 30:61-72.

Hemsworth, P. H., G. J. Coleman, J. L. Barnett, and S. Borg. 2000. Relationships between human-animal interactions and productivity of commercial dairy cows. J. Anim. Sci. 78:2821-2831.

Hill, N. P., P. E. Murphy, A. J. Nelson, N. Mouttotou, L. E. Green, and K. L. Morgan. 1997. Lameness and foot lesions in adult British dairy goats. Vet. Rec. 141:412-416.
Hoffman, A. C., D. A. Moore, J. Vanegas, and J. R. Wenz. 2014. Association of abnormal hind-limb postures and back arch with gait abnormality in dairy cattle. J. Dairy Sci. 97:2178-2185. http:// dx.doi.org/10.3168/jds.2013-7528.

Hughes, J. 2001. A system for assessing cow cleanliness. In Pract. $23: 517-524$.

Huzzey, J. M., D. M. Veira, D. M. Weary, and M. A. G. von Keyserlingk. 2007. Prepartum behavior and dry matter intake identify dairy cows at risk for metritis. J. Dairy Sci. 90:3220-3233. http:// dx.doi.org/10.3168/jds.2006-807.

Ito, K., N. Chapinal, D. M. Weary, and M. A. G. von Keyserlingk. 2014. Associations between herd-level factors and lying behavior of freestall-housed dairy cows. J. Dairy Sci. 97:2081-2089. http:// dx.doi.org/10.3168/jds.2013-6861.

Jackson, K. M. A., and D. Hackett. 2007. A note: The effects of human handling on heart girth, behaviour and milk quality in dairy goats. Appl. Anim. Behav. Sci. 108:332-336.

Jago, J. G., C. C. Krohn, and L. R. Matthews. 1999. The influence of feeding and handling on the development of the human-animal interactions in young cattle. Appl. Anim. Behav. Sci. 62:137-151.

Jefferies, B. C. 1961. Body condition scoring and its use in management. Tasmanian J. Agric. 32:19-21.

Jensen, M. B., and R. Kyhin. 2000. Play behavior in group-housed dairy calves, the effect of space allowance. Appl. Anim. Behav. Sci. $67: 35-46$

Jimenez-Granado, R., M. Sanchez-Rodriguez, C. Arce, and V. Rodriguez-Estevez. 2014. Factors affecting somatic cell count in dairy goats: A review. Span. J. Agric. Res. 12:133-150. http://dx.doi. org/10.5424/sjar/2014121-3803.

Johnsen, P. F., T. Johannesson, and P. Sandøe. 2001. Assessment of farm animal welfare at herd level: Many goals, many methods. Acta Agric. Scand. Anim. Sci. 30(Suppl.):26-33.

Jørgensen, G. H. M., I. L. Andersen, and K. E. Bøe. 2007. Feed intake and social interactions in dairy goats - The effects of feeding space and type of roughage. Appl. Anim. Behav. Sci. 107:239-251.

Kamboj, M. L., V. K. Vishwakarma, and A. Singh. 2007. Abnormal behaviours in dairy cattle and buffaloes: causes and their management. Indian Dairyman 59:27-33.

Kamphaus, R. W., and P. J. Frick. 2005. Clinical Assessment of Child and Adolescent Personality and Behavior. 2nd ed. Springer, New York, NY

Klaas, I. C., C. Enevoldsen, M. Vaarst, and H. Houe. 2004. Systematic clinical examinations for identification of latent udder health types in Danish dairy herds. J. Dairy Sci. 87:1217-1228.

Knierim, U., and C. Winckler. 2009. On-farm welfare assessment in cattle: Validity, reliability and feasibility issues and future perspectives with special regard to the Welfare Quality ${ }^{\circledR}$ approach. Anim. Welf. 18:451-458.

Koop, G., C. A. Collar, N. Toft, M. Nielen, T. van Werven, D. Bacon, and I. A. Gardner. 2013. Risk factors for subclinical intramammary infection in dairy goats in two longitudinal field studies evaluated by Bayesian logistic regression. Prev. Vet. Med. 108:304-312. http://dx.doi.org/10.1016/j.prevetmed.2012.11.007.

Koop, G., M. Nielen, and T. van Werven. 2012. Diagnostic tools to monitor udder health in dairy goats. Vet. Q. 32:37-44.

Kougioumtzis, A., G. E. Valergakis, G. Oikonomou, G. Arsenos, and G. Banos. 2014. Profile and genetic parameters of dairy cattle locomotion score and lameness across lactation. Animal 8:20-27. http://dx.doi.org/10.1017/S1751731113001717.

Krieg, A., and E. Peterhans. 1990. Caprine arthritis-encephalitis in Switzerland: Epidemiological and clinical studies. Schweiz. Arch. Tierh. 132:345-352.

Laister, S., N. Brörkens, S. Lolli, D. Zucca, U. Knierim, M. Minero, E. Canali, and C. Winckler. 2009. Reliability of measures of agonistic behaviour in dairy and beef cattle. Pages 95-112 in in Welfare Quality ${ }^{\circledR}$ Report No. 11-Assessment of Animal Welfare Measures for Dairy Cattle, Beef Bulls and Veal Calves. B. Forkman and L. Keeling, ed. Cardiff University, Cardiff, UK.

Laporte-Broux, B., C. Duvaux-Ponter, S. Roussel, J. Promp, P. Chavatte-Palmer, and A. A. Ponter. 2011. Restricted feeding of goats 
during the last third of gestation modifies both metabolic parameters and behavior. Livest. Prod. Sci. 138:74-88.

Leach, K. A., U. Knierim, and H. R. Whay. 2009a. Condition scoring for dairy and beef cattle and veal calves. Pages 1-6 in Welfare Quality Report No. 11-Assessment of Animal Welfare Measures for Dairy Cattle, Beef Bulls and Veal Calves. B. Forkman and L. Keeling, ed. Cardiff University, Cardiff, UK.

Leach, K. A., U. Knierim, and H. R. Whay. 2009b. Cleanliness scoring for dairy and beef cattle and veal cattle. Pages 25-30 in Welfare Quality Report No. 11-Assessment of Animal Welfare Measures for Dairy Cattle, Beef Bulls and Veal Calves. B. Forkman and L. Keeling, ed. Cardiff University, Cardiff, UK.

Leitner, G., N. Silanikove, and U. Merin. 2008. Estimate of milk and curd yield loss of sheep and goats with intramammary infection and its relation to somatic cell count. Small Rumin. Res. 74:221225 .

Lengarite, M. I., P. N. Mbugua, C. K. Gachuiri, and L. W. Kabuage. 2012. Herders' knowledge on mineral nutrition and implication on sheep and goat productivity in Marsabit South District, Kenya. Livest. Res. Rural. Dev. 24. Accessed Jul. 15, 2013. http://www. lrrd.org/lrrd24/4/leng24057.htm.

Lensink, B. J., X. Fernandez, X. Boivin, P. Pradel, P. Le Neindre, and I. Vessier. 2000. The impact of gentle contacts on ease of handling, welfare, and growth of calves and the quality of veal meat. J. Anim. Sci. 78:1219-1226.

Lensink, B. J., S. Raussi, X. Boivin, M. Pyykkonen, and I. Veissier. 2001. Reactions of calves to handling depend on housing condition and previous experience with humans. Appl. Anim. Behav. Sci. 70:187-199. http://dx.doi.org/10.1016/S0168-1591(00)00152-0.

Lima, M. S., R. A. Pascoal, and G. T. Stilwell. 2012b. Glycaemia as a sign of the viability of the foetuses in the last days of gestation in dairy goats with pregnancy toxaemia. Ir. Vet. J. 65:1 http:// www.irishvetjournal.org/content/65/1/1.

Lima, M. S., R. A. Pascoal, G. T. Stilwell, and C. A. Hjerpe. 2012a. Clinical findings, blood chemistry values, and epidemiologic data from dairy goats with pregnancy toxemia. Bovine Pract. 46:102110

Loretz, C., B. Wechsler, R. Hauser, and P. Rüsch. 2004. A comparison of space requirements of horned and hornless goats at the feed barrier and in the lying area. Appl. Anim. Behav. Sci. 87:275-283.

Lyons, D. M., and E. O. Price. 1987. Relationships between heart rates and behaviour of goats in encounters with people. Appl. Anim. Behav. Sci. 18:363-369.

Lyons, D. M., E. O. Price, and G. P. Moberg. 1988. Individual differences in temperament of domestic goats: Consistency and change. Anim. Behav. 36:1323-1333.

Main, D. C. J., Z. E. Barker, K. A. Leach, N. J. Bell, H. R. Whay, and W. J. Browne. 2010. Sampling strategies for monitoring lameness in dairy cattle. J. Dairy Sci. 93:1970-1978. http://dx.doi. org/10.3168/jds.2009-2500.

Main, D. C. J., J. P. Kent, F. Wemelsfelder, E. Ofner, and F. A. M. Tuyttens. 2003. Applications for methods of on-farm welfare assessment. Anim. Welf. 12:523-528.

Manteuffel, G., P. Birger, and P. C. Schön. 2004. Vocalization of farm animals as a measure of welfare. Appl. Anim. Behav. Sci. 88:163182. http://dx.doi.org/10.1016/j.applanim.2004.02.012.

Mantova, E. 2012. La presenza di ascessi come indicatore di benessere negli allevamenti caprini da latte. BSc Thesis. University of Milan, Milan, Italy.

Marsden, M. D., and D. G. M. Wood-Gush. 1986. The use of space by group housed sheep. Appl. Anim. Behav. Sci. 15:178.

Martin, P. R., and P. Bateson. 2007. Measuring Behaviour: An Introductory Guide. Cambridge University Press, Cambridge, UK.

Martínez-de la Puente, J., I. Moreno-Indias, A. Morales-Delanuez, M. D. Ruiz-Díaz, L. E. Hernández-Castellano, N. Castro, and A. Argüello. 2011. Effects of feeding management and time of day on the occurrence of self-suckling in dairy goats. Vet. Rec. 168:378-382. http://dx.doi.org/10.1136/vr.c6483.

Mason, G., and M. Mendl. 1993. Why is there no simple way of measuring animal welfare? Anim. Welf. 2:301-319.
Mason, G., and J. Rushen. 2006. Stereotypic Animal Behaviour: Fundamentals and Applications to Welfare. 2nd ed. CABI Publishing, Wallingford, UK

Mattiello, S., M. Battini, E. Andreoli, and S. Barbieri. 2011. Breed differences affecting dairy cattle welfare in traditional alpine tie-stall husbandry systems. J. Dairy Sci. 94:2403-2407. http://dx.doi. org/10.3168/jds.2010-3606.

Mattiello, S., M. Battini, E. Andreoli, M. Minero, S. Barbieri, and E. Canali. 2010. Technical note. Avoidance distance test in goats: A comparison with its application in cows. Small Rumin. Res. 91:215-218. http://dx.doi.org/10.1016/j.smallrumres.2010.03.002.

Mattiello, S., E. Canali, V. Ferrante, M. Caniatti, F. Gottardo, G. Cozzi, I. Andrighetto, and M. Verga. 2002. The provision of solid feed to veal calves: II. Behavior, physiology and abomasal damage. J. Anim. Sci. 80:367-375.

Mattiello, S., S. Villa, and G. Cioccarelli. 2008. Effetto delle modalità di gestione dell'alimentazione sul benessere del capretto. Large Anim. Rev. 4:202.

Mavrogianni, V. S., P. I. Menzies, I. A. Fragkou, and G. C. Fthenakis. 2011. Principles of mastitis treatment in sheep and goats. Vet. Clin. North Am. Food Anim. Pract. 27:115-120.

Mazurek, M., M. Marie, and D. Desor. 2005. Animal-centred indicators of dairy goat welfare. ISAH 2005, 1. Warsaw, Poland. Accessed Jul. 15, 2013. http://www.isah-soc.org/documents/2005/ sections/28_vol_1.pdf.

Mazurek, M., M. Marie, and D. Desor. 2007. Potential animal-centred indicators of dairy goat welfare. Anim. Welf. 16:161-164.

Mazurek, M., M. McGee, M. A. Crowe, D. J. Prendiville, X. Boivin, and B. Earley. 2011. Consistency and stability of behavioural fear responses of heifers to different fear-eliciting situations involving humans. Appl. Anim. Behav. Sci. 131:21-28.

McGregor, B. A. 2002. Extent and source of short and cotted mohair. RIRDC Research Paper, Rural Industries Research and Development Corporation, Barton, ACT, 02/108. RIRDC, Australia.

McGregor, B. A., and K. L. Butler. 2008. Relationship of body condition score, live weight, stocking rate and grazing system to the mortality of Angora goats from hypothermia and their use in the assessment of welfare risks. Aust. Vet. J. 86:12-17.

Menzies, P. I., and S. Z. Ramanoon. 2001. Mastitis of sheep and goats. Vet. Clin. North Am. Food Anim. Pract. 17:333-358.

Minero, M., M. A. Tosi, E. Canali, and F. Wemelsfelder. 2009. Quantitative and qualitative assessment of the response of foals to the presence of an unfamiliar human. Appl. Anim. Behav. Sci. 116:74-81.

Miranda-de la Lama, G. C., and S. Mattiello. 2010. The importance of social behaviour for goat welfare in livestock farming. Small Rumin. Res. 90:1-10.

Mononen, J., S. H. Møller, S. W. Hansen, A. L. Hovland, T. Koistinen, L. Lidfors, J. Malmkvist, C. M. Vinke, and L. Ahola. 2012. The development of on-farm welfare assessment protocols for foxes and mink: The WelFur project. Anim. Welf. 21:363-371.

Mount, L. E. 1979. Adaptation to Thermal Environment: Man and his Productive Animals. Edward Arnold, London, UK.

Muri, K. S. M. Stubsjøen, and P. S. Valle. 2013. Development and testing of an on-farm welfare assessment protocol for dairy goats. Anim. Welf. 22:385-400. http://dx.doi.org/10.7120/09627286.22.3.385.

Nagy, D. W., and D. G. Pugh. 2012. Handling and examining sheep and goats. Pages 1-17 in Sheep and Goat Medicine. 2nd ed. Elsevier Saunders, Maryland Heights, MO.

Napolitano, F., G. de Rosa, A. Girolami, M. Scavone, and A. Braghieri. 2011. Avoidance distance in sheep: test-retest reliability and relationship with stockmen attitude. Small Rumin. Res. 99:81-86.

Napolitano, F. U. Knierim, F. Grasso, and G. de Rosa. 2009. Positive indicators of cattle welfare and their applicability to on-farm protocols. Ital. J. Anim. Sci. 8:355-365.

Nielsen, B. L., A. B. Lawrence, and C. T. Whittemore. 1995. Effect of group size on feeding behavior, social behavior, and performance of growing pigs using single-space feeders. Livest. Prod. Sci. $44: 75-85$

Nordmann, E., N. M. Keil, C. Schmied-Wagner, C. Graml, J. Langbein, J. Aschwanden, J. von Hof, K. Maschat, R. Palme, and S. 
Waiblinger. 2011. Feed barrier design affects behaviour and physiology in goats. Appl. Anim. Behav. Sci. 133:40-53.

O'Callaghan, K. A., P. J. Cripps, D. Y. Downham, and R. D. Murray. 2003. Subjective and objective assessment of pain and discomfort due to lameness in dairy cattle. Anim. Welf. 12:605-610.

Ogebe, P. O., B. K. Ogunmodede, and L. R. McDowell. 1996. Behavioral and physiological responses of Nigerian dwarf goats to seasonal changes of the humid tropics. Small Rumin. Res. 22:213-217.

Olofsson, J. 1999. Competition for total mixed diets fed for ad libitum intake using one or four cows per feeding station. J. Dairy Sci. 82:69-79.

Paape, M. J., G. R. Wiggans, D. D. Bannerman, D. L. Thomas, A. H. Sanders, A. Contreras, P. Moroni, and R. H. Miller. 2007. Monitoring goat and sheep milk somatic cell counts. Small Rumin. Res. 68:114-125.

Paterna, A., A. Contreras, J. Gómez-Martín, J. Amores, M. TatayDualde, J. C. Prats-van der Ham, A. Corrales, C. Sánchez, and C. De la Fe. 2013. The diagnosis of mastitis and contagious agalactia in dairy goats. Small Rumin. Res. http://dx.doi.org/10.1016/j. smallrumres.2013.12.002.

Perrin, G. G., M. P. Mallereau, D. Lenfant, and C. Baudry. 1997. Relationships between California Mastitis Test (CMT) and somatic cell counts in dairy goats. Small Rumin. Res. 26:167-170.

Phythian, C. J., E. Michalopoulou, J. Duncan, and F. Wemelsfelder. 2013. Inter-observer reliability of qualitative behavioural assessments of sheep. Appl. Anim. Behav. Sci. 144:73-79. http:// dx.doi.org/10.1016/j.applanim.2012.11.011.

Phythian, C. J., E. Michalopoulou, P. H. Jones, A. C. Winter, M. J. Clarkson, L. A. Stubbings, D. Grove White, P. J. Cripps, and J. S. Duncan. 2011. Validating indicators of sheep welfare through a consensus of expert opinion. Animal 5:943-952.

Plummer, P. J., and J. A. Schleining. 2013. Assessment and management of pain in small ruminants and camelids. Vet. Clin. North Am. Food Anim. Pract. 29:185-208.

Welfare Quality. 2009a. Welfare Quality ${ }^{\circledast}$ Assessment Protocol for cattle. Welfare Quality Consortium, Lelystad, the Netherlands.

Welfare Quality. 2009b. Welfare Quality ${ }^{\circledR}$ Assessment Protocol for pigs. Welfare Quality Consortium, Lelystad, the Netherlands.

Rahardja, D. P., A. L. Toleng, and V. S. Lestari. 2011. Thermoregulation and water balance in fat-tailed sheep and Kacang goat under sunlight exposure and water restriction in a hot and dry area. Animal 5:1587-1593.

Reimert, I., J. E. Bolhuis, B. Kemp, and T. B. Rodenburg. 2013. Indicators of positive and negative emotions and emotional contagion in pigs. Physiol. Behav. 109:42-50.

Reneau, J. K., A. J. Seykora, B. J. Heins, M. I. Endres, R. J. Farnsworth, and R. F. Bey. 2005. Association between hygiene scores and somatic cell scores in dairy cattle. J. Am. Vet. Med. Assoc. 227:1297-1301.

Rook, A. J., and P. D. Penning. 1991. Synchronization of eating, ruminating and idling activity by grazing sheep. Appl. Anim. Behav. Sci. 32:157-166.

Rossi, R., and E. Scharrer. 1992. Circadian patterns of drinking and eating in pygmy goats. Physiol. Behav. 51:895-897.

Rousing, T., and S. Waiblinger. 2004. Evaluation of on-farm methods for testing the human-animal relationship in dairy herds with cubicle loose housing systems - Test-retest and inter-observer reliability and consistency to familiarity of test person. Appl. Anim. Behav. Sci. 85:215-231.

Rushen, J., A. Butterworth, and J. C. Swanson. 2011. Animal behavior and well-being symposium. Farm animal welfare assurance: Science and application. J. Anim. Sci. 89:1219-1228.

Russel, A. J. F., J. M. Doney, and R. G. Gunn. 1969. Subjective assessment of body fat in live sheep. J. Agric. Sci. 72:451-454.

Rutherford, K. M. D., R. D. Donald, A. B. Lawrence, and F. Wemelsfelder. 2012. Qualitative Behavioural assessment of emotionality in pigs. Appl. Anim. Behav. Sci. 139:218-224.

Santucci, P., A. Branca, M. Napoleone, R. Bouche, G. Aumont, F. Poisot, and G. Alexandre. 1991. Body condition scoring of goats in extensive conditions. Pages $240-255$ in Goat Nutrition. P. Mo-
rand-Fehr, ed. Wageningen Academic Publishers, Wageningen, the Netherlands.

Sarkar, M., S. A. Rahman, B. K. Sarker, A. Anisuzzaman, N. Begum, and M. M. H. Mondal. 2010. Epidemiology and pathology of ectoparasitic infestations in Black Bengal goats in Gaibandha and Mymensingh districts of Bangladesh. Bangladesh J. Vet. Med. $8: 41-50$.

Schlumbohm, C., and J. Harmeyer. 2008. Twin-pregnancy increases susceptibility of ewes to hypoglycaemic stress and pregnancy toxaemia. Res. Vet. Sci. 84:286-299.

Schreiner, D. A., and P. L. Ruegg. 2003. Relationship between udder and leg hygiene scores and subclinical mastitis. J. Dairy Sci. 86:3460-3465.

Scott, K., D. J. Chennells, D. Armstrong, L. Taylor, B. P. Gill, and S. A. Edwards. 2007. The welfare of finishing pigs under different housing and feeding systems: Liquid versus fry feeding in fullyslatted and straw-based housing. Anim. Welf. 16:53-62.

Sejian, V., and R. S. Srivastava. 2010. Effects of melatonin on adrenal cortical functions of Indian goats under thermal stress. Vet. Med. Int. 2010:348919. http://dx.doi.org/10.4061/2010/348919.

Shackleton, D. M., and C. C. Shank. 1984. A review of the social behavior of feral and wild sheep and goats. J. Anim. Sci. 58:500-509.

Shamay, A., F. Shapiro, H. Barash, I. Bruckental, and N. Silanikove. 2000. Effect of dexamethasone on milk yield and composition in dairy cows. Ann. Zootech. 49:343-352.

Shinde, A. K., D. L. Verma, and N. P. Singh. 2004. Social dominancesubordinate relationships on a flock of Marwari goats. Indian J. Anim. Sci. 74:216-219.

Siebert, K., J. Langbein, P. C. Schön, A. Tuchscherer, and B. Puppe. 2011. Degree of social isolation affects behavioral and vocal response patterns in dwarf goats (Capra hircus). Appl. Anim. Behav. Sci. 131:53-62.

Silanikove, N. 2000. Effects of heat stress on the welfare of extensively managed domestic ruminants: A review. Livest. Prod. Sci. 67:1-18.

Smith, M. C., and D. M. Sherman. 2009. Goat Medicine. 2nd ed. Wiley-Blackwell, Ames, IA.

Stelwagen, K., and C. H. Knight. 1997. Effect of unilateral once or twice daily milking of cows on milk yield and udder characteristics in early and late lactation. J. Dairy Res. 64:487-494.

Stricklin, W. R., H. B. Graves, and L. L. Wilson. 1979. Some theoretical and observed relationships of fixed and portable spacing behavior in animals. Appl. Anim. Ethol. 5:201-214.

Thomsen, P. T., L. Munksgaard, and F. A. Tøgersen. 2008. Evaluation of a lameness scoring system for dairy cows. J. Dairy Sci. 91:119-126. http://dx.doi.org/10.3168/jds.2007-0496.

Torres, A., N. Castro, L. E. Hernández-Castellano, A. Argüello, and J. Capote. 2013. Short communication: Effects of milking frequency on udder morphology, milk partitioning, and milk quality in 3 dairy goat breeds. J. Dairy Sci. 96:1071-1074.

Toussaint, G. 1997. The housing of milk goats. Livest. Prod. Sci. 49:151-164.

Tuyttens, F. A. M., M. Sprenger, A. Van Nuffel, W. Maertens, and S. Van Dongen. 2009. Reliability of categorical versus continuous scoring of welfare indicators: Lameness in cows as a case study. Anim. Welf. 18:399-405.

Van, D. T. T., N. T. Mui, and I. Ledin. 2007. Effect of group size on feed intake, aggressive behavior and growth rate in goat kids and lambs. Small Rumin. Res. 72:187-196.

Varner, M. A., and B. H. Johnson. 1983. Influence of adrenocorticotropin upon milk production, milk constituents, and endocrine measures of dairy cows. J. Dairy Sci. 66:458-465.

Veit, H. P., F. Mccarthy, J. Friedericks, M. Cashin, and R. Angert. 1993. A survey of goat, and cattle diseases in the Artibonite Valley, Haiti, West Indies. Rev. Elev. Med. Vet. Pay. 46:27-38.

Waiblinger, S., X. Boivin, V. Pedersen, M. Tosi, A. M. Janczak, E. K. Visser, and R. B. Jones. 2006. Assessing the human-animal relationship in farmed species: A critical review. Appl. Anim. Behav. Sci. 101:185-242.

Waiblinger, S., C. Schmied-Wagner, D. Mersmann, and E. Nordmann. 2011. Social behaviour and injuries in horned and hornless dairy 
goats. Pages 421-422 in Proc. XV Congress of the International Society for Animal Hygiene, Vienna, Austria.

Wemelsfelder, F. 2007. How animals communicate quality of life: The qualitative assessment of animal behaviour. Anim. Welf. 16:2531.

Wemelsfelder, F., F. Millard, G. de Rosa, and F. Napolitano. 2009. Qualitative behaviour assessment. Pages 215-224 in Welfare Quality ${ }^{\circledR}$ Report No. 11-Assessment of Animal Welfare Measures for Dairy Cattle, Beef Bulls and Veal Calves. B. Forkman and L. Keeling, ed. Cardiff University, Cardiff, UK.

Whay, H. R., D. C. Main, L. E. Green, and A. J. F. Webster. 2003. Assessment of the welfare of dairy cattle using animal-based measurements: Direct observations and investigation of farm records. Vet. Rec. 153:197-202.

Winckler, C. 2006.On-farm welfare assessment in cattle-From basic concepts to feasible assessment systems. Pages 493-500 in Proc.
XXIV World Buiatrics Congress, Nice, France. Gloyd Group, Wilmington, DE.

Winckler, C., J. Capdeville, G. Gebresenbet, B. Hörning, U. Roiha, M. Tosi, and S. Waiblinger. 2003. Selection of parameters for on-farm welfare-assessment protocols in cattle and buffalo. Anim. Welf. $12: 619-624$.

Windschnurer, I., C. Schmied, X. Boivin, and S. Waiblinger. 2009. Assessment of human-animal relationships in dairy cows. Pages in 137-152 in Welfare Quality ${ }^{\oplus}$ Report No. 11-Assessment of Animal Welfare Measures for Dairy Cattle, Beef Bulls and Veal Calves. B. Forkman and L. Keeling, ed. Cardiff University, Cardiff, UK.

Winter, A. C. 2008. Lameness in sheep. Small Rumin. Res. 76:149153.

Winter, A. C. 2011. Treatment and control of hoof disorders in sheep and goats. Vet. Clin. North Am. Food Anim. Pract. 27:187-192. 